\title{
Applications of Game Theory in Project Management: A Structured Review and Analysis
}

\author{
Mahendra Piraveenan (1) \\ Faculty of Engineering, University of Sydney, Sydney, NSW 2006, Australia; \\ mahendrarajah.piraveenan@sydney.edu.au
}

Received: 30 July 2019; Accepted: 4 September 2019; Published: 17 September 2019

\begin{abstract}
This paper provides a structured literature review and analysis of using game theory to model project management scenarios. We select and review thirty-two papers from Scopus, present a complex three-dimensional classification of the selected papers, and analyse the resultant citation network. According to the industry-based classification, the surveyed literature can be classified in terms of construction industry, ICT industry or unspecified industry. Based on the types of players, the literature can be classified into papers that use government-contractor games, contractor-contractor games, contractor-subcontractor games, subcontractor-subcontractor games or games involving other types of players. Based on the type of games used, papers using normal-form non-cooperative games, normal-form cooperative games, extensive-form non-cooperative games or extensive-form cooperative games are present. Also, we show that each of the above classifications plays a role in influencing which papers are likely to cite a particular paper, though the strongest influence is exerted by the type-of-game classification. Overall, the citation network in this field is sparse, implying that the awareness of authors in this field about studies by other academics is suboptimal. Our review suggests that game theory is a very useful tool for modelling project management scenarios, and that more work needs to be done focusing on project management in ICT domain, as well as by using extensive-form cooperative games where relevant.
\end{abstract}

Keywords: decision-making; game theory; project management

\section{Introduction}

A project is a time-bound exercise undertaken by on organisation to obtain a product, service or result. "Project management" is defined by the PMBoK (Project Management Body of Knowledge) as "a temporary endeavour to create a unique product, service or result" [1-3]. The concept of project management has evolved through several schools of thought, and uses a range of theories originating from mathematics, computer science, economics, and other related fields in its modelling and analysis.

Sensible decision-making is critical for the success of projects [1-3]. Every project begins with a decision: the decision to invest. Often, an investor has several investment options, and each option will result in a different project, and thus one of the investment options has to be chosen before the project charter can be produced. Similarly, any large project involving subcontractors, for instance, a construction project, has a complex interplay between the main contractor (the project manager) and subcontractors, or among the subcontractors themselves, which typically has several decision points. For example, if there is an ambiguity in the contract between the contractor and subcontractor, each must decide how hard to push their case without jeopardising the whole project, and thus their own stake in it. Similarly, when projects from competing organisations are launched, the marketing personnel have to decide what is the best timing and strategy to market the project, or its resultant product or service, so that it can gain maximum traction in the face of competition. In each of these 
scenarios described above, the required decisions depend on the decisions of others who, in some way, have competing interests to the interests of the decision-maker.

Project management uses a range of concepts and tools in decision-making. These include investment analysis methods such as force field analysis, the life cycle cost method, internal rate of return etc., and other tools such as utility theory, prospect theory, Net Present Value (NPV) method, Monte Carlo analysis, linear programming, queueing theory and so on [4,5]. Recently, game theory [6-11] has been gaining prominence as a tool useful in decision-making in project management scenarios $[12,13]$. Compared to the other tools mentioned above, game theory is particularly useful in scenarios where a number of entities are trying to achieve the same outcome (either in competition with each other, or in cooperation with each other), but have independent and rational decision-making abilities. Thus, it is especially useful in decision-making in the face of competition, particularly in scenarios such as those described above. Game theory also offers a rigorous mathematical framework, and has been successfully used in fields such as economics, social science, biology and computer science, presenting many precedents and examples for project management researchers to follow. Thus, papers analysing project management scenarios have arisen in the past decade, to use game theory in their modelling. It is, however, a nascent field, and the purpose of this review is to advocate for the widespread use of game theory as a modelling and analysis tool in project management, by summarising the state-of-the-art in this niche, classifying the existing works and highlighting gaps in the literature and opportunities for future research.

There is a considerable (but not overwhelming) body of work which has attempted to use game theory in modelling project management scenarios. There is even a hypothesis (the "Bilton and Cummings" hypothesis) that states, "the use of game theory makes it possible to understand the needs and interests of the involved persons in a better way and to finalize the project successfully" [14,15]. Papers which use game theory in project management relate to construction projects, information and communications technology (ICT) projects and projects from other domains. They use various types of games, and model a diverse range of players such as governments, project managers/contractors, subcontractors and clients. Therefore, a well-structured review of the field becomes necessary to comprehend the state-of-the-art, classify existing studies and identify gaps in the literature. To our knowledge, such a review spanning several application domains yet focusing exclusively on project management and games does not exist. Indeed, there are works such as Kaplinski and Tamosaitiene [16], which focus on reviewing the work of individual authors or research groups or reviewing aspects of the use of game theory in operations research, which has some relevance to project management; still, a structured review focusing on the use of game theory in project management in all its domains and applications is lacking. Therefore, we present such a review here.

We select papers that use game theory in project management scenarios from the Scopus database using a rigorous selection process, and review and analyse these papers in great detail. We also analyse the relative impact of each paper to the particular niche of "game theory in project management", and to project management research is general. We introduce and use a complex multidimensional, yet principled, classification scheme that helps to highlight the areas where most effort has been exerted to date and areas where there are gaps in the literature. We also consider citation networks of the papers in the niche, and show how these networks can be related to and explained by the classification scheme that we present. Our review and analysis highlight why game theory is a very useful tool to model project management scenarios, and in what further ways it could be applied in project management contexts in the future.

In summary, the significance of this review is attested by the following aspects.

- We follow a comprehensive and principled method for searching and filtering relevant papers.

- We review papers across several disciplines, such as construction, ICT and education, and highlight the similarities and differences between them in their application of game theory in project management.

- We present a detailed multidimensional classification of the papers that we have reviewed. 
- We present and analyse the citation network of the papers we have reviewed, highlighting their interdependency and relative impact.

- We identify gaps in the literature that point to potentially fruitful future research directions.

Overall, our review not only presents descriptions of the papers that we have considered, but also an in-depth analysis of the field.

The rest of this paper is organised as follows. In Section 2, we review relevant concepts in project management and game theory, which are alluded to throughout this paper. In Section 3, we describe the process by which papers were selected from Scopus to be included in this review. In Section 4 we describe how the reviewed papers can be classified and the justification for our classifications. In Section 5, we describe the papers that we review, summarise their findings, and compare their findings. In Section 6, we analyse the relative importance of the papers that we have reviewed by constructing citation networks among the papers reviewed, and comment on how the citation networks are influenced by the classification(s) of the papers. Finally, in Section 7, we summarise our findings, identify gaps in literature and directions of high potential for future research and provide our conclusions. In the rest of the paper, we use the terms "the niche" or "the field" to refer to the particular area of research that we are reviewing: the application of game theory in project management.

\section{Background}

\subsection{Project Management}

The concept of project management is well known, but for the sake of completeness, we give a brief overview here. Projects are the results of organisations responding to threats, such as market forces, regulatory requirements, financial constraints or opportunities such as competitive advantage, compliance or operational efficiency [1-3]. Essentially, when an organisation undertakes a project, it deviates from its "business as usual" mode and, through a time-bound transition, moves to a state which becomes the new "business as usual" at project completion. Projects are usually classified as mandatory, business critical, discretionary or stewardship projects $[1,2,17]$. The theory of project management has undergone an evolutionary process in the last several decades, with several schools of thought gaining prominence from time to time, such as the optimisation school of thought, the governance school of thought, the modelling school of thought, the decision school of thought, etc. $[1,18,19]$.

\subsection{Game Theory}

Game theory, which is the study of strategic decision making, was first developed as a branch of microeconomics $[6,7,9,20]$. However, later, it has been adopted in diverse fields of study, such as evolutionary biology, sociology, psychology, political science and computer science [21-24]. Game theory is used to study many phenomena and behavioural patterns in human societies and socio-economical systems, such as the emergence and sustaining of cooperation in communities and organisations [22,25-28], modelling of unethical or criminal behaviour [29,30] or the decision-making processes involved in vaccination against epidemics [31-33]. Game theory has gained such wide applicability due to the prevalence of strategic decision-making scenarios across different disciplines. A typical game defined in game theory has two or more players, a set of strategies available to these players, and a corresponding set of pay-off values (sometimes called utility values) for each player (which are, in the case of two-player games, often presented as a pay-off-matrix). Game theory can be classified into two broad domains: non-cooperative game theory and cooperative game theory.

\subsubsection{Non-Cooperative Games and Cooperative Games}

Typically, games are played for the self-interest of the players, even when the players cooperate; cooperation is the best strategy under the circumstances to maximise the individual pay-offs of the players. In such games, the cooperative behaviour, if it emerges, is driven by selfish goals and is 
transient. These games can be termed "non-cooperative games". Non-cooperative game theory is the branch of game theory that analyses such games. On the other hand, in a cooperative game, or coalitional game, players form coalitions, or groups, often due to external enforcement of cooperative behaviour, and competition is between these coalitions [10,34,35]. Cooperative games are analysed using cooperative game theory, which predicts the coalitions that will form and the pay-offs of these coalitions. Cooperative game theory focuses on surplus or profit sharing among the coalition members, where the coalition is guaranteed a certain amount of pay-off by virtue of the coalition being formed. Often, the outcome of a cooperative game played in a system is equivalent to the result of a constrained optimisation process [36], and therefore many of the papers we review use a linear programming framework to solve the cooperative games they model.

\subsubsection{Nash Equilibrium}

Nash equilibrium is one of the core concepts in (non-cooperative) game theory. It is a state (a set of strategies) in a strategic game from which no player has an incentive to deviate unilaterally, in terms of pay-offs. Both pure strategy and mixed strategy Nash equilibria can be defined. A strategic game can have more than one Nash equilibrium [10,37]. It is proven that every game with a finite number of players in which each player can choose from finitely many pure strategies has at least one Nash equilibrium [37].

The formal definition of Nash equilibrium is as follows. Let $(S, f)$ be a game with $n$ players, where $S_{i}$ is the strategy set of a given player $i$. Thus, the strategy profile $S$ consisting of the strategy sets of all players would be $S=S_{1} \times S_{2} \times S_{3} \ldots . \times S_{n}$. Let $f(x)=\left(f_{1}(x), \ldots . ., f_{n}(x)\right)$ be the pay-off function for strategy set $x \in S$. Suppose $x_{i}$ is the strategy of player $i$ and $x_{-i}$ is the strategy set of all players except player $i$; thus, when each player $i \in 1, \ldots . ., n$ chooses strategy $x_{i}$ that would result in the strategy set $x=\left(x_{1}, \ldots ., x_{n}\right)$, giving a pay-off of $f_{i}(x)$ to that particular player, which depends on both the strategy chosen by that player $\left(x_{i}\right)$ and the strategies chosen by other players $\left(x_{-i}\right)$. A strategy set $x^{*} \in S$ is in Nash equilibrium if no unilateral deviation in strategy by any single player would return a higher utility for that particular player [38]. Formally put, $x^{*}$ is in Nash equilibrium if and only if

$$
\forall i, x_{i} \in S_{i}: f_{i}\left(x_{i}^{*}, x_{-i}^{*}\right) \geq f_{i}\left(x_{i}, x_{-i}^{*}\right)
$$

\subsubsection{Zero-Sum Games}

Zero-sum games are a class of non-cooperative games where the total of the pay-offs of all players is zero. In two player games, this implies that one player's loss in pay-off is equal to another player's gain in pay-off. A two-player zero-sum game can therefore be represented by a pay-off matrix, which shows only the pay-offs of one player. Zero-sum games can be solved with the mini-max theorem [39], which states that in a zero-sum game there is a set of strategies which minimises the maximum losses (or maximises the minimum pay-off) of each player. This solution is sometimes referred to as a "pure saddle point". It can be argued that the stock market is a zero-sum game. In contrast, most valid economic transactions are non-zero-sum, since each party considers that what it receives is more valuable (to itself) than what it parts with.

\subsubsection{Common Interest Games}

Common interest games are another class of non-cooperative games in which there is an action profile that all players strictly prefer over all other profiles [40]. In other words, in common interest games, the interests of players are perfectly aligned. It can be argued that common interest games are the antithesis of zero-sum games in which the interests of the players are perfectly opposed, so that any increase in fortune for one player must necessarily result in the collective decrease in fortune for others. Common interest games were first studied in the context of cold war politics, to understand and prescribe strategies for handling international relations [41-43]. 
It makes sense to classify non-cooperative games into common interest games and non-common interest games, just as much as it makes sense to classify them into zero-sum games and non-zero sum games, since these two concepts (zero-sum games and common interest games) represent extreme cases of non-cooperative games. However, the papers we reviewed do not use common interest games to model project management scenarios, and it would be rare to find scenarios in project management where the interests of players are perfectly aligned. Therefore, we do not use the common interest games-based classification in our classification process, as it would add another dimension and increase the complexity of classification needlessly.

\subsubsection{Normal-Form Games and Extensive-Form Games}

In a normal-form game, only a single round of decision-making takes place, where all players make decisions simultaneously. An extensive-form game is, on the other hand, an iterative game where there are several rounds of decision-making $[44,45]$. On each round, players could make decisions simultaneously or in some predefined order. An extensive-form game is often represented by a game tree, where each node (except terminal nodes) is a decision point, and each link corresponds to a decision or a set of decisions that could be made by the relevant player/players at that point. The terminal nodes represent an end to the extensive-form game, corresponding to pay-offs for each player involved.

\subsubsection{Simultaneous Games and Sequential Games}

A simultaneous game is either a normal-form game or an extensive-form game where on each iteration, all players make decisions simultaneously. Therefore, each player is forced to make the decision without knowing about the decisions made by other players (on that iteration). On the contrary, a sequential game is a type of extensive-form game where players make their decisions (or choose their strategies) in some predefined order [44,45]. For example, a negotiation process can be modelled as a sequential game if one party always has the privilege of making the first offer; the other parties make their offers or counteroffers after that. In a sequential game, at least some players can observe at least some of the actions of other players before making their own decisions (otherwise, the game becomes a simultaneous game, even if the moves of players do not happen simultaneously in time). However, it is not required that every move of each previous player should be observable to a given player. If a player can observe every move of every previous player, such a sequential game is known to have "perfect information"; otherwise, the game is known to have "imperfect information". Sequential games are often used by papers that we are reviewing here, to model bargaining or negotiation processes.

\subsubsection{Subgames}

A subgame is a subset of a sequential game, such that at its beginning, every player knows all the actions of the players that preceded it [6]. That is, a subgame is a section of the game tree of a sequential game where the first decision node that belongs to this section has perfect information.

\subsubsection{Subgame Perfect Nash Equilibrium}

In a sequential game, a subgame perfect Nash equilibrium is a set of strategies representing each player such that they constitute a Nash equilibrium for every subgame of that sequential game [6]. Thus, when a game tree of the sequential game is considered, if a set of strategies could be identified so that they represent a Nash equilibrium for every branch of game tree originating from a node representing a point where every player knows all preceding actions of all players, such a set of strategies represent a subgame perfect Nash equilibrium for that sequential game. For example, when two players are bargaining, they are in a subgame perfect Nash equilibrium if they are presently employing a set of strategies, which will represent a Nash equilibrium between them at any future 
stage of the bargaining process given that they are aware of the full history of the bargaining process up to that point.

\subsubsection{Stackelberg Games}

A Stackelberg game is a particular type of two player sequential game commonly used in economics [46]. In a Stackelberg game, there is a leader and a follower, which are typically companies operating in a market. The leader's firm has some sort of market advantage that enables it to move first and make the first decision, and the follower's optimal decision depends on the leader's decision. If a follower chose a non-optimal action given the action of the leader, it will adversely affect not only the pay-off of the follower, but the pay-off of the leader as well. Therefore, the optimal decision of the leader is made on the assumption that the follower is able to see the leader's action and that it will act to maximise its own pay-off given the leader's action. Several papers we review here have used Stackelberg games to model project management scenarios.

\subsubsection{Nash Bargaining}

In a Nash bargaining game [47], sometimes referred to as a bargaining problem or bargaining game, two players could choose from an identical set of alternatives, however each alternative has varying pay-offs for the players. Typically, some alternatives have better pay-off for one player, whereas other alternatives have better pay-off for the other player. If both players choose the same alternative, then each get the pay-off corresponding to that alternative. If they choose differing alternatives, then there is no agreement, and they each get a fixed pay-off which corresponds to the cost of non-agreement, and therefore typically negative. Thus, there is incentive to choose an alternative which may not necessarily be the best for a player. If there is perfect information, that is, the full set of alternatives and pay-offs is known to both players, then there is an equilibrium solution to the Nash bargaining game [48].

\subsubsection{Evolutionary Game Theory}

Evolutionary game theory is an outcome of the adoptation of game theory into the field of evolutionary biology [49,50]. Some of the critical questions asked in evolutionary game theory follow. Which populations/strategies are stable? which strategies can 'invade' (become popular) in populations where other strategies are prevalent? How do players respond to other players receiving or perceived to be receiving better pay-offs in an iterated game setting? Evolutionary games are often modelled as iterative games where a population of players play the same game iteratively in a well-mixed or a spatially distributed environment [38,51].

A strategy can be identified as an evolutionary stable strategy (ESS) if, when prevalent, it has the potential to prevent any mutant strategy from percolating its environment [38]. Alternatively, an ESS is the strategy which, if adopted by a population in a given environment, cannot be invaded by any alternative strategy. Hence, there is no benefit for a player to switch from an ESS to another strategy. Therefore, essentially, an ESS ensures an extended Nash equilibrium. For strategy, $S_{1}$, to be ESS against another "invading" strategy, $S_{2}$, one of the two conditions mentioned below needs to be met, in terms of expected pay-off, $E$.

1. $E\left(S_{1}, S_{1}\right)>E\left(S_{2}, S_{1}\right)$ : By unilaterally changing strategy to $S_{2}$, the player will lose out against another player who sticks with the ESS $S_{1}$.

2. $E\left(S_{1}, S_{1}\right)=E\left(S_{2}, S_{1}\right) \& E\left(S_{1}, S_{2}\right)>E\left(S_{2}, S_{2}\right)$ : a player, by converting to $S_{2}$, neither gains nor loses against another player who sticks with the ESS $S_{1}$, but playing against a player who has already "converted" to $S_{2}$, a player is better off playing the ESS $S_{1}$.

If either of these conditions are met, the new strategy $S_{2}$ is incapable of invading the existing strategy $S_{1}$, and thus $S_{1}$ is an ESS against $S_{2}$. Evolutionary games are typically modelled as iterative games, whereby players in a population play the same game iteratively. 


\section{Selection Methodology}

In this section, we describe how we have selected the papers to review and classify. The papers were selected from the Scopus database [52], with any paper which was cited by one of the papers selected from Scopus but not in Scopus itself, and which satisfied all the selection criteria as described below, also being "manually" included. The selection of papers from the Scopus database included a four-step process.

1. Scopus database was searched for a number of key phrases, as elaborated below, and all papers deemed relevant in this search were downloaded. A total of 776 papers were downloaded and considered in this manner.

2. A brief manual screening was conducted considering the title and abstract of the papers, selecting some papers for detailed inspection. A total of 72 papers remained at the end of this stage.

3. After detailed reading of each paper, some papers were excluded from our review and classification, as described below. A total of 25 papers remained at the end of this stage.

4. The reference list of each remaining paper was considered, and checked against the list of papers already excluded. If a paper was not already excluded or not in Scopus, then it went through steps 2 and 3 of the screening process, and included in our review and classification if selected. At the end of this step, 32 papers were selected for inclusion in this review.

Clearly, it must be acknowledged that such a selection process has some limitations: it only considers papers from Scopus or papers having some citation relationship with the papers in Scopus, and it is also, implicitly, focused on papers which are published in international journals and internationally recognised conferences, which are more likely to be included in Scopus, as opposed to regionally focused papers or papers which are published in regional outlets. Therefore, the search is not exhaustive, and there may be other papers of merit. Nevertheless, the selection process is principled and represents at least a very significant section of the field, including almost all papers which have had international research impact.

Now we describe each step of this selection process in more detail.

\subsection{Step 1}

In step one, the following combinations of key phrases were used in Scopus to search the database and select the relevant papers. Only the titles of the papers were searched.

1. ("game theo*") and ("project management" or "construction management" or "* contract")

2. ("decision") and ("project management" or "construction management" or "* contract")

3. ("games") and ("project management" or "construction management" or "*contract")

These key phrases were selected so that papers having "construction management" or '1contract management" instead of "project management" in the title could also be considered. After deleting the duplicates, a total of 776 papers were found and downloaded.

\subsection{Step 2}

In step two, the title and abstract of each of the 776 papers are selected in the previous step were manually considered, and papers were selected according to the following criteria.

1. Title: those papers having titles where the keywords have been used in a different context were omitted. For example, if the word "game" was used in the sense of video game, computer game or other simulated game, those papers were omitted. Similarly, papers with titles where the word "contract" was used in a context not related to project management were omitted.

2. Abstract: Those papers which had abstracts that made it clear that the paper deals with ongoing operational issues, and not project management issues, were omitted. 
3. English language: only records written in English were further considered. Records nominally written in English where the quality of the narrative was so poor as to not make sense to a reasonable native English speaker, were also excluded. Papers which had their title and/or abstract in English, but the body of the paper in another language, were also excluded.

4. Availability: Papers which were not publicly available (either freely, or for a fee) were excluded. Note, papers that were publicly available for a fee were not excluded. Only those papers which did not have the full content publicly available freely or for a fee were excluded.

5. In cases where two very similar papers by the same authors were found, where one paper is an extension of the other but included all content of the previous paper, only the later (and thus the more 'matured') paper was considered. For example, if a conference publication was later developed into a journal paper by the inclusion of additional material, the conference paper was excluded and only the journal paper was considered.

At the end of step 2, 72 papers were selected for complete and careful scrutiny.

\subsection{Step 3}

In this step, each of the remaining 72 papers was carefully and completely read and considered; papers were excluded if they use game theory in operational management scenarios, but not necessarily in project management particularly. To this end, the definition of project management as a time-bound activity was considered important [1-3], and thus papers describing the use of game theory to model day-to-day operational issues, or the 'business-as-usual' operation of the company, were excluded. For example, a paper describing the negotiation process between an airline and a freight forwarder using game theory was excluded [53]; this negotiation reflects the routine business operations of both parties, which they do not necessarily need to implement a project to undertake. Papers were also excluded if it was possible that a project management application may exist for their modelling, but they did not explicitly describe such an application. In Section 5.3, we describe some of the papers which passed stage 2 and were excluded at stage 3, so that the interested reader may appreciate why such papers were excluded, and how they may still be of some relevance. However, we do not classify these papers, as per the reasons described for each individual paper later, we consider them out of scope for this review.

It should also be pointed out that a considerable body of management-related literature exists in fields such as physics and sociology, which uses game theory. For example, the incentives for cooperation in society as well as organisations have been studied from a rigorous statistical mechanics point of view, in papers such as the works by the authors of [28,54], or from a systemic point of view, in papers such as the work by the authors of [55-58]. However, such papers also would be out of the scope of this review due to the definition of project management as a time-bound exercise, which we strictly adhere to in selecting papers to review. In other words, these papers do not clearly distinguish project management from organisational management, which is concerned with the day-to-day "business as usual" of the organisation, and as such, these papers are not within scope of this review. Nevertheless, the interested reader is referred to the above-mentioned papers which highlight some interesting overlaps between game theory and the concept of management as perceived in other fields.

\subsection{Step 4}

In this step, we compiled a combined list of references from the 25 papers in step 3, using a simple computer script. From this list, any paper selected in step 1 (selected from Scopus based on the key phrases) was excluded. The remaining papers were either not in Scopus or were in Scopus but not selected in step 1. Then, these papers were put through steps 2 and 3 (above), respectively (that is, title and abstract scan, and selected papers to detailed reading), and seven papers were selected after step 3. These seven papers were added to the pool of twenty-five papers already selected at stage 4 . This step is used to ensure that any relevant paper cited by other papers in the niche, but is not present in Scopus or selected in keyword search, is considered. 
Therefore, after step 4 , a total of $25+7=32$ papers remained, which are reviewed and classified in this study, as described below.

\section{Classification of the Selected Papers}

We propose that the selected papers shall be classified as follows.

- Classification based on the application domain

- Classification based on the players of the game

- Classification based on the type of game played

\subsection{Classification Based on the Application Domain}

Here, we propose that, based on the domain of the industry in which it is applied, papers undertaking game-theoretic analysis of project management can be classified into three classes.

- $\quad$ Papers focusing on project management in construction projects

- Papers focusing on project management in ICT (Information and Communications Technology) projects

- Papers focusing on project management in other fields or generic project management

\subsection{Classification Based on Players of the Games}

In any game-theoretic modelling of real world, the "players" of the game usually represent some real world being or entity. When game theory is used in project management, the players of the game usually represent investors, project managers, contractors, subcontractors, the government or other individuals or organisations involved in running the project. Since a game needs multiple players, several combinations of above-mentioned individuals can be represented in a game, and a complex classification of games is possible based on these combinations. Fortunately, most of the papers we reviewed use two-player games, and even when the number of players is more than two, the types of players present in a game is usually restricted to two. Therefore, the games present in the literature can be classified based on the following combinations of players. In our terminology, and for classification purposes, a "contractor" is the governing entity of a project which makes decisions on behalf of the project, variously called project manager, main contractor, private company or contractor in the literature. We distinguish a contractor from a "subcontractor" in the sense that the contractor is responsible for the overall delivery of the project, represents the project and makes decisions for the overall benefit of the project, whereas a subcontractor is responsible for one particular task or aspect of the project. Thus we propose the following classification.

- Papers focusing on contractor-contractor games (including investment decision games)

- Papers focusing on contractor-subcontractor games

- Papers focusing on contractor-government games (sometimes called Public-Private Partnerships, where the phrase 'public' represents the government and 'private' represents the private company which is the contractor)

- Papers focusing on subcontractor-subcontractor games

- Papers focusing on games with other player combinations

\subsection{Classification Based on the type of Game Played}

Here, we propose a complex matrix classification. On one-hand, games employed in game theory can be classified into non-cooperative games and cooperative games. One subclassification of non-cooperative games is zero-sum games and non zero-sum games. Zero-sum games cannot by definition exist in a cooperative game, as if the total pay-off for the community is by definition zero, it cannot be a fixed (non-zero) value and it cannot be shared. Another possible subclassification of non-cooperative games is common interest games and non-common interest games, but since 
the papers we review do not use common interest games, this subclassification is not necessary here. Both non-cooperative games and cooperative games are used by papers reviewed here. On the other hand, games can also be classified into normal-form games and extended-form games. Both normal-form games and extended-form games are used in the papers we review here.

Therefore, a matrix classification with four categories is possible: normal-form non-cooperative games, normal-form cooperative games, extensive-form non-cooperative games and extensive-form cooperative games. Normal-form non-cooperative games have two subclasses: normal-form non-cooperative zero-sum games and normal-form non-cooperative non-zero-sum games. Similarly, extensive-form non-cooperative games have two subclasses: extensive-form non-cooperative zero-sum games, and extensive-form non-cooperative non-zero-sum games. The resultant complex matrix can be used to classify the papers according to the type of game used.

These classifications, containing the relevant papers, are shown (Note that, in order to conserve space, a naming convention is used in the figures, which is different from the standard nomenclature and that used in the text of the paper. In the text of the paper, a paper by a single author is denoted by their surname, a paper by two authors is denoted by both their surnames, whereas a paper by three or more authors is denoted as "surname-of-first author et al.", as is the normal convention. To add further clarification, the publication year is also mentioned-for example, Peldschus et al., 2010. In figures however, to conserve space, the papers are denoted simply by the surname of first author and the publication year, regardless of the number of authors. For example, Peldschus et al., 2010 is simply denoted as Peldschus 2010. In either case, an alphabet is added if the same set of authors published more than one paper in the same year. For example, 'Bergantinos and Sanchez, $2002 \mathrm{a}$ ' is one of two papers published by these two authors in 2002, which is simply denoted as 'Bergantinos $2002 \mathrm{a}$ ' in the figures. ) in Figures 1-3. Since these classifications are overlapping, each paper that we reviewed is present in some class of each classification. Therefore, overall, it could be argued that the reviewed literature is best captured in a multidimensional complex classification.

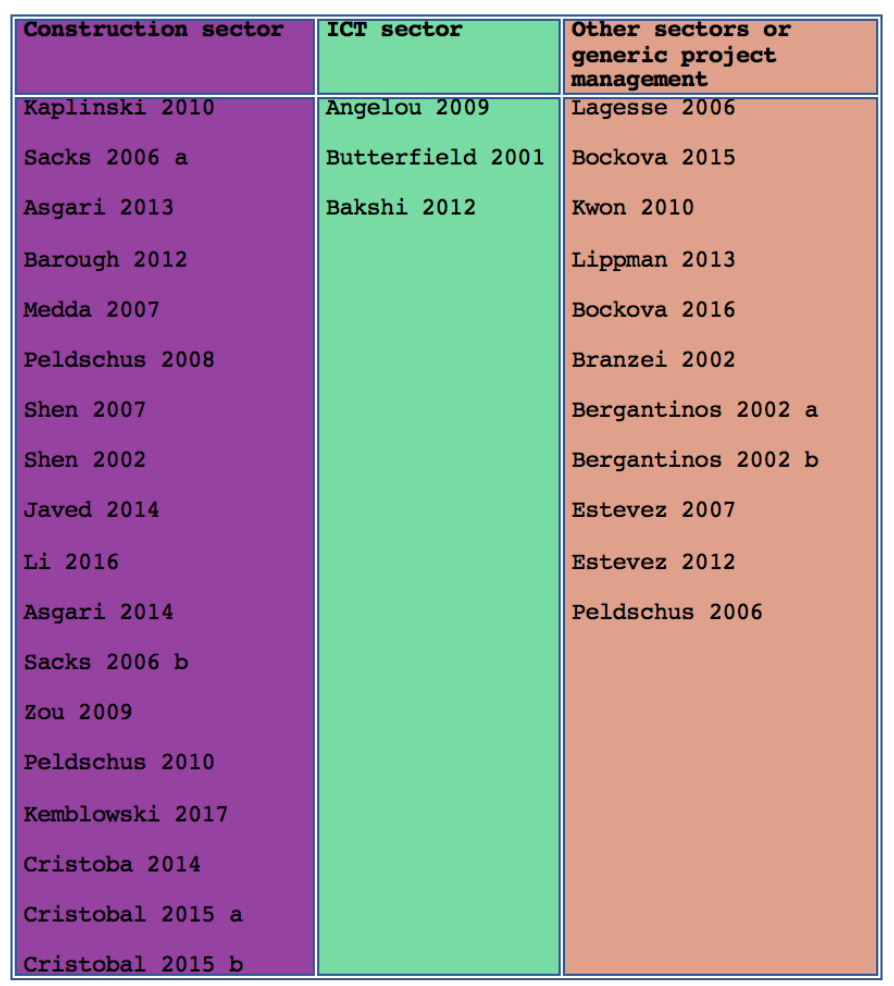

Figure 1. The classification of papers reviewed based on the application domain. 


\begin{tabular}{|c|c|c|c|c|}
\hline $\begin{array}{l}\text { Government } \\
\text { sector - } \\
\text { Private } \\
\text { sector game } \\
\text { (Public - } \\
\text { Private } \\
\text { partnership } \\
\text { ) }\end{array}$ & $\begin{array}{l}\text { Contractor - } \\
\text { contractor } \\
\text { game }\end{array}$ & $\begin{array}{l}\text { Contrac } \\
\text { tor - } \\
\text { subcont } \\
\text { ractor } \\
\text { game }\end{array}$ & $\begin{array}{l}\text { Subcontractor - } \\
\text { subcontractor game }\end{array}$ & $\begin{array}{l}\text { Other } \\
\text { players }\end{array}$ \\
\hline $\begin{array}{l}\text { Medda } 2007 \\
\text { Shen } 2002 \\
\text { Shen } 2007 \\
\text { Javed } 2014 \\
\text { Li } 2016 \\
\text { Zou } 2009 \\
\text { Bockova } \\
2016\end{array}$ & $\begin{array}{l}\text { Kaplinski } \\
2010 \\
\text { Angelou } 2009 \\
\text { Bockova } 2015 \\
\text { Butterfield } \\
2001 \\
\text { Bakshi } 2012 \\
\text { Kemblowski } \\
2017 \\
\text { Peldschus } \\
2006\end{array}$ & $\begin{array}{l}\text { Sacks } \\
2006 \text { a } \\
\text { Barough } \\
2012 \\
\text { Kwon } \\
2010 \\
\text { Lippman } \\
2013 \\
\text { Sacks } \\
2006 \text { b }\end{array}$ & $\begin{array}{l}\text { Asgari } 2013 \\
\text { Cristoba } 2014 \\
\text { Cristobal } 2015 \text { a } \\
\text { Asgari } 2014 \\
\text { Cristobal } 2015 \text { b } \\
\text { Branzei } 2002 \\
\text { Bergantinos } 2002 \text { a } \\
\text { Bergantinos } 2002 \text { b } \\
\text { Estevez } 2007 \\
\text { Estevez } 2012\end{array}$ & $\begin{array}{l}\text { Lagesse } \\
2006 \\
\text { Peldschus } \\
2008 \\
\text { Peldschus } \\
2010\end{array}$ \\
\hline
\end{tabular}

Figure 2. The classification of papers reviewed based on the players of the games.

\begin{tabular}{|c|c|c|c|}
\hline & \multicolumn{2}{|c|}{ Non Co-operative game } & \multirow{2}{*}{ Co-operative game } \\
\hline & Zero-sum & Non zero-sum & \\
\hline 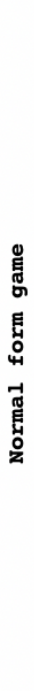 & $\begin{array}{l}\text { Kaplinski } 2010 \\
\text { Peldschus } 2008 \\
\text { Peldschus } 2010\end{array}$ & $\begin{array}{l}\text { Barough } 2012 \\
\text { Medda } 2007 \\
\text { Bockova } 2015 \\
\text { Bockova } 2016 \\
\text { Kemblowski } 2017\end{array}$ & $\begin{array}{l}\text { Lagesse } 2006 \\
\text { Cristoba } 2014 \\
\text { Cristobal } 2015 \text { a } \\
\text { Cristobal } 2015 \text { b } \\
\text { Zou } 2009 \\
\text { Bakshi } 2012 \\
\text { Branzei } 2002 \\
\text { Bergantinos } 2002 \text { a } \\
\text { Bergantinos } 2002 \text { b } \\
\text { Estevez } 2007 \\
\text { Estevez } 2012 \\
\text { Peldschus } 2006 \\
\text { Asgari } 2013 \\
\text { Asgari } 2014\end{array}$ \\
\hline 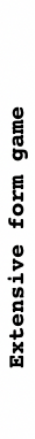 & & $\begin{array}{l}\text { Sacks } 2006 \text { a } \\
\text { Kwon } 2010 \\
\text { Angelou } 2009 \\
\text { Shen } 2002 \\
\text { Shen } 2007 \\
\text { Butterfield } 2001 \\
\text { Javed } 2014 \\
\text { Li } 2016 \\
\text { Lippman } 2013\end{array}$ & Sacks $2006 \mathrm{~b}$ \\
\hline
\end{tabular}

Figure 3. The classification of papers reviewed based on the type of game played. 
Overall, the rest of the paper is structured based on the game-based classification. Nevertheless, some papers use more than one type of game. In this case, the paper is described in the subsection which is most relevant, as it is pointless to describe the same paper in multiple sections. Similarly, some papers also use more than one type of player combination or may belong to more than one application domain, though these classifications are not used to structure this review. It should be noted that the Figures 1-3 highlight each paper according to its most relevant classification.

\section{Description of the Papers Reviewed}

In this section, we review the 32 papers selected and classified above, following the game-based classification to structure the review.

\subsection{Papers Using Normal-Form Games}

As shown in Figure 3, there are in total 22 papers using normal-form games.

\subsubsection{Papers Using Normal-Form Non-Cooperative Games}

As shown in Figure 3, there are eight papers using normal-form non-cooperative games.

Papers using normal-form non-cooperative zero-sum games: In this section, we describe papers which exclusively use zero-sum games, or their primary modelling uses zero-sum games, within the normal-form non-cooperative game category. As shown in Figure 3, there are three such papers.

Peldschus et al. (2010) [59] apply game theory in construction management, for the specific task of selecting a suitable construction site. It can be argued that construction management is a branch of project management, as most construction works are time-bound, and thus can be considered as projects. Peldschus et al. (2010) define a number of selection criteria, and construct a zero-sum game where the choices for potential construction sites are modelled as 'strategies' of one player, while the choices for selection criteria (such as price per square metre, total area, reputation/appeal of area, soak density, etc.) are modelled as the 'strategies' of another player. Then they present the mini-max solution for this game. The mini-max solution could be justified by the following argument (though such an argument is not explicitly presented in the paper). In the face of uncertainty about what sites the other player will choose, each player will take a minimal risk approach and accept the mini-max solution; that is, each player will take the solution that maximises the minimal value of the site (where the minimal value is obtained by comparing values according to a number of criteria), given uncertainty about other players' (builders') choices. The mini-max solution is modelled within the context of a zero-sum game, based on the assumption that summation of the intrinsic value of all construction sites available is constant, therefore all criteria must result in the same total value across all sites (therefore, if compared to criteria $C_{1}$, criteria $C_{2}$ increases the value of alternative (site) $A_{1}$ by $u$ dollars, then all other alternatives (sites) assessed according to criteria $C_{2}$ must in total face a value reduction of $u$ compared to criteria $C_{1}$. In this sense, this game could be called a constant-sum game rather than a zero-sum game). However, the above line of justification holds only when the competing investors are represented as players, whereas Peldschus et al. (2010) models a two player zero-sum game where the players have no corresponding real world roles.

Peldschus (2008) [12] presents a mix of theoretical frameworks and practical examples to demonstrate the use of game theory in construction project management. Partially a review of his previous works, his study focuses in particular on zero-sum games applied on investment decision scenarios, where the strategies of one "player" represent the available investment options (alternatives), whereas the strategies of the other player represents different investment evaluation methods (criteria). This representation of players is similar to his representation [59], described above. In this sense, the two players do not represent two human actors but rather two dimensions of the problem analysed, and thus the approach differs from most other studies in this field, or indeed in most other fields where game theory is applied. He also demonstrates the use of fuzzy games, and provides several real world examples where he demonstrates the application of the methods introduced. 
Kaplinski and Tamosaitiene (2010) [16] reviewed the research of one particular academic (Professor Peldschus mentioned above) in the area of the application of game theory in construction engineering and management. Nevertheless, even though the particular academic has apparently done seminal work in the field, this article, which reviews one academic's work, obviously cannot be considered a comprehensive review of the field. The individual contributions of the particular academic mentioned in this review are reviewed individually in our own review, whenever such contributions are in English and satisfy our selection criteria for inclusion in this review as mentioned in Section 3. This paper discusses both zero-sum and non-zero-sum games in the construction management context, but mainly focuses on zero-sum games, as it discusses papers such as the work by the authors of $[12,59]$ described above.

Papers using normal-form non-cooperative non-zero-sum games: There are five papers in our review, which exclusively or primarily use normal-form non-cooperative non-zero-sum games to model scenarios in project management, as shown in Figure 3.

Medda (2007) [60] uses game theory to model the allocation of risks between governments and private companies in public-private partnership projects as a bargaining process. Specifically, this process is modelled as a final offer arbitration game. Their particular focus is on Public-Private Partnership (PPP) projects in transport infrastructure. The "final offer arbitration" is an arbitration process designed to avoid court litigation, wherein the parties or arbitrator have no authority to further negotiate, but make a decision based on the final offers made by all parties concerned, making it ideal for game-theoretic modelling. Unlike many similar papers [61-64] that model bargaining processes using extensive-form games; Medda (2007) is able to use a normal-form non-cooperative game specifically because they focus on final offer arbitration. Medda (2007) presents a detailed analytical model and pay-off model, and calculates the equilibrium solution of the game-based on these.

Kemblowski et al. (2017) [65] use game theory, specifically normal-form non-cooperative non-zero-sum games, to model the bidding process for a highway construction project. The bidding process is further complicated by the fact that there are hidden costs in the project (such as the cost of purchasing a gravel pit). They show that the solution of this game depends on the probability of the hidden costs being non-zero, and for a certain range of this probability there are pure strategy equilibria, and beyond which there are mixed strategy equilibria. This brief paper is very specific in addressing only a well-defined and hypothetically formulated problem, which might be more extensive and complex in real world settings.

Bockova et al. (2015) [15] analyses the utility of game theory as a tool to manage educational projects in the Czech republic, during a specific period in time which they term "the post-conflict period". The paper is not a methodical literature review, but a combination of examples, results from other papers and results of interviews and surveys conducted by the authors. It essentially attempts to present and justify the case for game theory to be used as a tool in project management, using diverse methods. The paper claims to validate the hypothesis presented in another work by Bilton and Cummings [14]: "The use of game theory makes it possible to understand the needs and interests of the involved persons in a better way and to finalize the project successfully." This paper can be included in the category of papers using normal-form non-cooperative non-zero-sum games, on the basis that many examples the paper describes seem to lend themselves to modelling by such games. The study by Bilton and Cummings [14] itself does not figure in our review, due to it being included in a book, which, overall, does not satisfy our criteria for inclusion, and is concerned rather with operations research.

Bockova et al. (2016) [66] also claim to verify the so-called Bilton and Cumming's hypothesis. They claim to do so by a mixture of reviewing a select set of papers as well as conducting interviews with and running surveys among industry experts. Unlike [15], however, this paper focuses on public-private partnerships in post-conflict Czech republic. This paper has aspects of a review, however it does not provide justification for how the papers it comments on were selected from the literature. The paper 
also details several scenarios where game theory might be applicable based on media stories and the authors' knowledge of the country in question: the Czech republic. Thus, this study is qualitative and illustrative in nature. It is also included in the category of papers using normal-form non-cooperative non-zero-sum games, on the basis that many examples the paper describes seem to use such games.

\subsubsection{Papers Using Normal-form Cooperative Games}

There are 14 papers using normal-form cooperative games in our review, as shown in Figure 3. In some of these papers, cooperative games are used to model a scenario where optimisation of some quantity (such as the project cost) under certain constraints is required. Such papers are most often not domain-specific, but nevertheless have several examples inspired from the construction industry.

In a construction project, each subcontractor working on it have periods where they can work more efficiently and thus be more cost effective, and sometimes it is possible to 'trade' time-periods between subcontractors so that overall cost effectiveness or time efficiency of projects increases. Asgari and Afshar (2008) [67] present a cooperative game, where a group of subcontractors working on a number of simultaneous projects can trade their time commitment to each project for the benefit of all players. The cooperative game they present can also be thought of as a constrained optimisation problem, where the project cost or time for completion is minimised by trading time between subcontractors. They conclude the study with an illustrative example.

Similarly, Asgari et al. (2013) [68] present a game-theoretic framework for resource management in construction projects. This paper analyses how subcontractors could cooperate among themselves and share resources for maximum resource utility and profit. Thus they use a normal-form cooperative game to model the scenario.

Lagesse (2006) [69] employs game theory for task assignment within a project. Specifically, they show how game theory can be used to develop an algorithm for task assignments to each employee within a project based on employee skills, time available to each employee, as well as employee and management preference. The algorithm they present also includes in-built feedback mechanisms. Interestingly, though the authors state this is a game-theoretic model, the algorithm they present is essentially a matching algorithm that produces a stable matching solution between the set of employees and the set of tasks at any point in time, and is game-theoretic only in the sense that the "stable matching solution" is essentially an equilibrium solution.

Cristoba (2014) [70] (It appears that the author of this paper has spelt their surname as Cristoba in some papers and Cristobal in others.) proposes a game-theoretic framework to identify the particular activities that were responsible for delays in a project, and accordingly split the cost of the project delay among the respective subcontractors of these activities. They present a multiplayer game and use a linear programming approach to solve it. In this sense, this paper presents an optimisation solution rather than an equilibrium solution. This is a feature of several papers which use cooperative games to model project management scenarios, both in normal-form and extended-form, as we will see below.

Cristobal (2015) [71] also proposes a game-theoretic model to identify activities that are responsible for delays in (primarily construction) projects, and apportion the costs associated with delays among these activities accordingly. Again, the game they propose is a cooperative game, which they solve by modelling it as a constrained linear optimisation problem: an approach very similar to [72-74]. The overall benefit to the project is considered as the optimisation criteria, and individual activities (or the subcontractors responsible for them) are assumed to give priority to the cooperative over their self-interest.

Cristobal (2015) [13] is a very broad review of management science methods and methodologies used in project management, and one of the techniques it discusses is the use of game theory. However, its discussion of the use of game theory in project management is very brief and without any examples, since the paper overall is fairly abstract. This paper however is part of the body of work contributed by Cristobal and thus mentioned and classified here along with his other works. 
Branzei et al. (2002) [75] focuses on cost sharing in delayed projects: specifically, how the costs associated with a delay can be "fairly" shared between the players who are individually and collectively responsible for a delay. Therefore, it could be argued that, rather than modelling the decision-making processes of the players involved, this study presents a cooperative game: an algorithm to share costs fairly, so that a ready justification for the cost allocation can be provided against the potential "protest" of selfish players. Thus their approach is broadly equivalent to solving a linear optimisation problem. Their approach, they say, is inspired by literature in bankruptcy and taxation, but their work itself is explicitly focused on project management. They present two cooperative games (which they term "coalitional" games), namely, the pessimistic delay game and the optimistic delay game. Both games are based on the activity graph of the project, and the cost sharing process is modelled as a game between activities of the project in the first game, and a game between paths in the activity graph in the second game. However, with their stated assumption that different agents (players) are responsible for different activities, and given that a player who is responsible for a specific activity in a project is typically a subcontractor, ultimately it could be argued that they model subcontractor-subcontractor games. This also holds true for several other papers which we review here, which adopt a similar approach, such as the works by the authors of [72-74]. Therefore, in Figure 2, these are all classified as papers that model subcontractor-subcontractor games.

Bergantinos and Sanchez (2002) [72] also consider how to share the additional cost of a project delay among the firms (subcontractors) responsible for it, using game theory. Again, following an approach similar to $[70,71,75]$, they formulate a "cost game" and use constrained optimisation techniques, utilising the "Shapley value" of the cost game. Therefore, this is an algorithm for fair allocation of costs that each subcontractor then needs to be convinced about, rather than an equilibrium solution reached by selfish behaviour of each subcontractor whereby the subcontractor will have no incentive to deviate from it. Therefore, the practical value of such an approach is as a fair algorithm rather than a model of the behaviour of (typically selfish) subcontractors who accept their part of the cost in delaying the project.

Bergantinos and Sanchez (2002) [76] use non-transferable utility (NTU) games to divide slack time into different activities of the project, within the context of Project Evaluation and Review Technique (PERT). In this sense, this work has similarities to works by the authors of [71-75], which use game-theoretic modelling to assign costs related to project delay among participating activities (or subcontractors responsible for those activities) in the project.

The work of Estevez-Fernandez et al. (2007) [73] is essentially a generalisation on work done in papers such as the works by the authors of $[71,72,75,76]$. It presents a cost sharing model in situations where some activities in a project do not run according to schedule. It presents three categories: (a) situations where some activities are delayed, (b) situations where some activities are expedited and (c) situations where some activities are delayed and others are expedited. It models each of these scenarios using "project games". They show that delayed project games have a nonempty core. The expedited project games are shown to be convex. In the third scenario where some activities may be delayed and some activities may be expedited, related project games are shown to have a nonempty core. Again, it could be argued that this study presents an algorithm for cost allocation rather than a behavioural game mimicking the behaviour of subcontractors and an equilibrium solution.

Estevez-Fernandez (2012) [74] is a further generalisation of Estevez-Fernandez et al. (2007) [73], which models not only models the costs associated with delays, but also the rewards associated with expediting some activities. Again, a set of project games are defined and "coreness" of these games is analysed. The cost and reward assignment is again undertaken by treating the project game as a constrained linear optimisation problem.

It should be noted here, therefore, that the above-mentioned six papers [71-76] have similar approaches, and, as we will show later, they cite each other. This group of papers form an important "core" in the literature of applications of game theory in project management, which shares the cost of delays and all use cooperative games, while presenting slight variations and extensions from each 
other. As the citation networks we present later show, these papers form the most densely connected subnetwork of the citation network in this field.

Zou and Kumarasawamy (2010) [77] use game theory to model aspects of Public-Private Partnerships (PPPs), including risk sharing, financial negotiation and operation. The first two are concerned with project management, while the third aspect is not directly a project management aspect, since it takes place after the project has been completed. Yet, due to the presence of the first two aspects, this paper falls within the ambit of our review. They assume that the behaviour of the public sector in their interactions with private sector is predictable, whereas the private sector can be unpredictable in its interactions with public sector, and that the utility for public sector is derived from socio-economic benefits, whereas the utility for private sector is derived solely from economic benefits. Because pay-offs are not modelled mathematically, this paper does not present a rigorous mathematical equilibrium solution for the games it proposes, and is thus can be more appropriately considered as a conceptual paper. It also claims to have used interviews with industry experts to guide its modelling.

Bakshi et al. (2012) [78] focuses on software engineering project management. They primarily focus on investment decisions; that is, which software project among a number of viable choices is the best to invest in. They convert the game-theoretic framework into a constrained linear optimisation problem which is equivalent to a cooperative game, and they solve it using linear programming. They use four well-known investment decision techniques in project management as "strategies" of the players in the game: Net Present Value (NPV) method, Rate Of Return (ROR) method, Payback Period (which they denote as PB) method, and Project Risk (which they denote as PR) method. They demonstrate an equilibrium solution, by obtaining pay-off values from what they call 'expert decision' and from literature which is outside the scope of this review, being in the domain of operations research rather than project management.

Peldschus (2006) [79] is an invited editorial to the proceedings of a conference, among the many topics which were discussed therein is the use of game theory in project management. This contribution gives a general overview of the use of game theory in project-management related scenarios, without making a specific research contribution or providing a structured analysis. However, it seems to refer primarily to scenarios similar to those studied in the above-mentioned papers, utilising cooperative games, and therefore this paper could be categorised with the above-mentioned papers in terms of the type of game discussed.

\subsection{Papers Using Extensive-Form Games}

Ten papers among the papers covered by this review use extensive-form games to analyse project management related scenarios, as shown in Figure 3. Many of these papers focus on multiround bargaining within the project management context.

\subsubsection{Papers Using eXtensive-Form Non-Cooperative Games}

Nine out of the ten papers which use extensive-form games use non-cooperative extensive-form games to model the project management scenarios they study.

Papers using extensive-form non-cooperative zero-sum games: We did not find any papers eligible for our review, as specified in Section 3, which use extensive-form non-cooperative zero-sum games.

Papers using extensive-form non-cooperative non-zero-sum games: Nine papers covered in this review use extensive-form non-cooperative non-zero sum games to model project management scenarios. Several of these papers model bargaining between competing entities (such as contractor and subcontractor, or private contractor and government), even though, assuming some solutions are better for all players on average compared to others, these games are not zero-sum.

Sacks and Harel (2006) [80] model the behaviour of subcontractors in terms of resource allocation by using game theory. This paper models the main contractor (or the project manager representing 
the main contractor) and the subcontractors undertaking various components of a construction project, as the protagonists playing a game with each other. The subcontractor often works in several projects at the same time, and the project manager engages several subcontractors to complete the construction work. The project manager tries to get the subcontractor to give priority to their project in resource allocation, so that they can meet the schedule of the project, while the subcontractor tries to allocate their resources in a way that brings them maximum utility and profit. The paper describes several equilibrium solutions, based on the level of information either party (main contractor or subcontractor) possesses.

Angelou and Economides (2009) [81] present a game-theoretic model for irreversible investment decisions in the ICT field, where each potential investor is a player. They show that either a leader-follower equilibrium or a simultaneous investment equilibrium may result in investments being made. They apply their method to a real-life case study where a particular Greek company (Egnatia Odos) considers its investment options in the ICT industry under intense competition from other companies.

Shen et al. (2002) and Shen et al. (2007) [61,62] apply game theory to a Build-Operate-Transfer (BOT) Construction model, which is typically governed by an agreement between a government and a private company. In the BOT model, the private company which builds the infrastructure recovers its costs and makes a profit by running whatever it just built for a certain period of time (known as the concession period), before handing the facility over to the government. Therefore, the length of concession period is always a subject of negotiation between the private firm and the host government, and Shen et al. [61,62] use game theory to determine this period. They model the bargaining process as an iterative game whereby the pay-off of the government decreases with the concession time, while the pay-off of the private company increases: however, there is another factor-the time taken to strike the deal itself — which both parties want to make shorter, because it is in both parties' interest to strike a deal as quickly as possible. This time pressure increases with each iteration, so that both parties know that it is better to strike a deal early and make some concession rather than adopt a hard line and risk many iterations. Using this model, Shen et al. [61,62] find the solution of the game, which calculates the concession period agreed upon as the "equilibrium" solution.

Butterfield and Pendegraft (2001) [82] use game theory and an extension of it, the theory of moves, to identify best investment decisions in the IT sector, in the face of competition from other investors. In particular, they model the fact that investors may take actions sequentially after observing others' actions by using the theory of moves, which differs from simultaneous games in that players are able to decide on their strategy after observing the other's strategy; thus, they play sequential games (Note well here that an extensive-form game can be either simultaneous game or sequential game. We have not considered this difference in our classification of the literature reviewed in this study, since that will add a further dimension and make the game-based classification too complex.). Butterfield and Pendegraft particularly model the scenario where a number of IT companies are considering investing in a new technology (so that the strategies available are to invest or not to invest), one of these strategies (to invest) is irreversible, and the pay-off for each strategy depends on what the other players decide to do, thus lending itself to a classical scenario for the theory of moves. The paper offers a number of valuable examples involving real-world IT companies or IT-related services where their modelling can be applied.

Javed et al. [63] use game theory to model change negotiations in Public-Private partnerships (PPP) during the concession period-the period during which the private partner raises revenue from the project, before handing it over to the government involved. They use a software called "Z-Tree" to simulate the changes that would trigger the change negotiations. They used actual people to make decisions in a game-theoretic scenario, where each game is an iterated ultimatum game played by two human subjects using a computer interface, one representing the government and the other representing the private firm, under multiple output specifications. The multiple output specifications for each change scenario described the same change in varying levels of detail. For each 
output specification, each party made multiple offers to foot a certain proportion of the cost of the change, and the equilibrium solution was reached when the parties agreed on the proportions of cost each party would accept, or when the change was abandoned. Data was collected and aggregated from these experiments. They concluded that the level of detail described in the output influences the strategies adopted by players in the iterative bargaining games.

$\mathrm{Li}$ et al. (2016) [64] illustrated the use of bargaining game theory for risk allocation in Public-Private Partnerships, by using iterative bargaining games. They use Harsanyi transformation theory to model incomplete information games, whereby each player cannot entirely predict the other's strategy but can estimate it using a subjective probability distribution. They highlight that the cost of bargaining increases with each iteration, at some point subsuming costs associated with the risks being negotiated about, so that an equilibrium solution will always be reached. They analyse the difference in outcome when the first round offer was made by the public sector and when the first round offer was made by the private sector. They show that being the first mover, and having better information about the likely strategy of the other player, are advantages that result in a smaller share of risk being allocated to that party.

Lippman et al. (2013) [83] present the cost sharing equilibrium solution between a risk-neutral project manager (main contractor) and a risk-averse sub contractor, when their negotiation process can be modelled by Nash bargaining. They consider a "1fixed fee plus fraction of cost" model, of which both fixed price contracts and "cost + fixed fee" contracts are subclasses, and show that the fixed fee and fraction of cost borne by the main contractor can both be derived as the solution of a Nash bargaining model. They assume that the pay-off for each party is zero if the project is not launched, so that a Nash bargaining equilibrium where the pay-offs are not zero will always be reached. They further assume that the solution of Nash bargaining maximizes the product (not summation) of the pay-offs for each party, which they term the "Nash product". They conclude that the (full) cost plus fixed fee type of contract dominates all other types of (fixed fee plus fraction of cost) contracts, in arriving at highest Nash product at equilibrium solution.

\subsubsection{Papers Using Extensive-Form Cooperative Games}

A single paper within the scope of our review, Sacks and Harel (2006) [84], uses an extensive-form cooperative game in modelling a project management scenario. Given that in construction projects, subcontractors will be reluctant to allocate their labour resources to a particular project if they perceive that the project plan or schedule is unreliable, Sacks and Harel explore the relationship between project plan reliability and subcontractor resource allocation behaviour using a game-theoretic framework. In particular, they use extended-form games to explore the trust between project managers (main contractors) and subcontractors, and demonstrate what level of trust in project plan is needed before this relationship changes from competitive to collaborative. In their model, the project manager estimates the work that the subcontractor needs to do during a particular phase, and then, without divulging this information, can demand a certain quantum of work from the subcontractor, which could in fact be lower, equal, or higher than the estimate of the project manager. The subcontractor could, in turn, allocate resources which are less than, equal to, or more than what is demanded (the last action will be in the hope that the project manager has either underestimated work or under-demanded resources, and more resources will be needed than what the project manager has demanded). The pay-offs for both parties will depend on the strategy adopted by both parties, even though they do not divulge to each other what strategy they have adopted. For example, if the project manager has over-demanded resources and the subcontractor oversupplied resources, the utility for the project manager will be high, since the work will be finished quickly and smoothly, but the utility for the subcontractor is low, because s/he will over-allocate and waste resources. The win-win scenario arises when the project manager demands just enough resources, and the contractor allocates what is demanded, but for this to happen, the level of trust between the parties should be high. Sacks and Harel quantify this relationship between trust and pay-off, and further show that through the 
transparent 'last planner' system they introduce, where the subcontractors are given active roles in project planning, the overall pay-off for all parties could be increased, and the game turns from a competitive (non-cooperative) one into a cooperative game. In this sense, the paper deals with an extensive-form cooperative game.

\subsection{Papers Relevant to Project Management but not Explicitly Set in Project Management Context}

In our paper selection process, several papers were excluded after stage 3, because they did not provide specific project management-related examples or they were applied in scenarios which were not time-bound, and thus related more to operations research than project management. Nevertheless, several of these papers could be of interest to project management professionals, or describe modelling techniques which could be reused in project management related scenarios. We briefly describe here, some of the papers which were excluded at stage 3 , so that the reader may appreciate why such papers were excluded, and how they may still be of some relevance. Note well though that this is merely a set of examples and not an exhaustive list of such papers which were excluded at stage 3 . The examples we consider are listed in Figure 4.

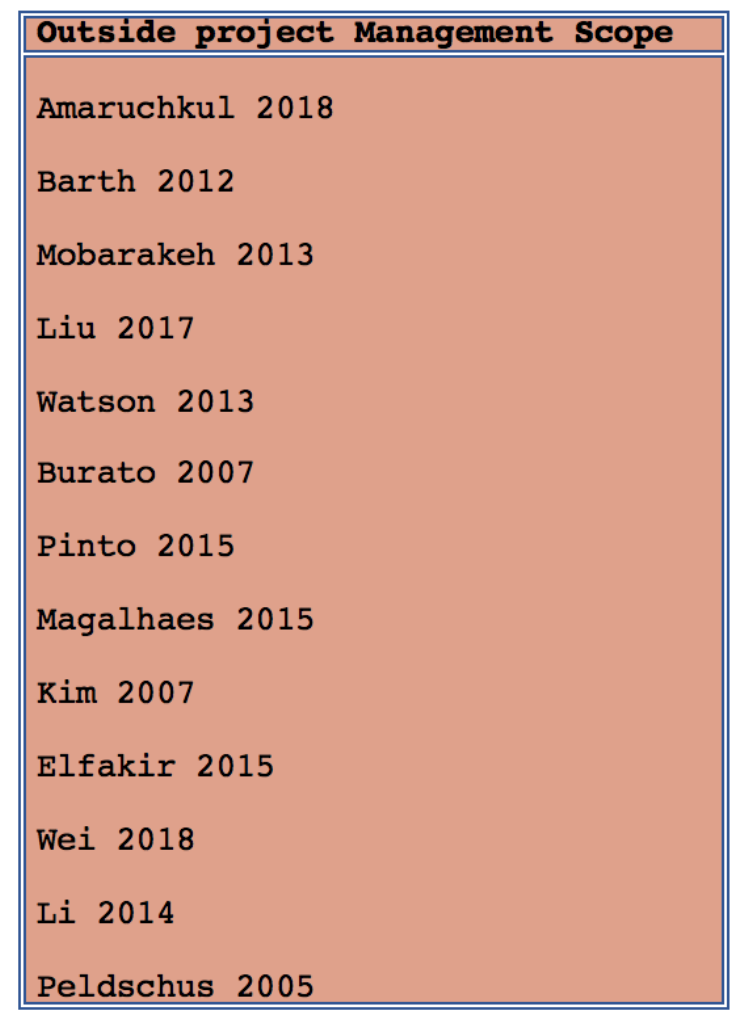

Figure 4. Some examples of papers which were not classified, as they were not project management-specific.

Amaruchkul (2008) [53] uses game theory to model contract negotiations between air cargo carriers and freight forwarders, which determine the size of allotments made by the carrier to each freight forwarder. The pay-off of the freight forwarded is decided by the rate it receives from the carrier for their cargo, and they hope to receive a discount rate compared to the spot rate by securing an allotment beforehand. The pay-off for the carrier is decided by maximum utility of space, and by giving allotments beforehand, the carrier seeks to ensure efficient utility of space. The equilibrium solution (for each game where a particular carrier and particular freighter is involved) indicates the size of the allotment made to that particular freight forwarder by the carrier. Amaruchkul demonstrates that this solution offers higher pay-offs to both parties compared to spot purchasing of space. The Stackleberg 
game they formulate can also be formulated as a constrained optimisation problem. The authors provide examples of analytical as well as numerical solutions.

Magalhaes et al. (2015) [85] produced a game-theoretic framework to assess the competency and integrity of academics in universities. They explain that given the academics are often expected to perform multiple activities, such as teaching, research, and administration, within a certain period of time, their competency in each of these areas of work must necessarily be assessed against the time they spend in each of these. They point out that given individual academics have preferences about each of these branches of work, if they were to be required to provide a timesheet about the time spent in each of these activities, it is necessary to verify the claims made in these time sheets against the incentive to do each of these activities, and they use game theory as a tool to achieve this aim. Given that academia is competitive, they postulate that the decision by an academic to spend a certain percentage of their time in each of these activities is a function of how they perceive their colleagues are allocating their time, more than what their contracts actually demand of them. They ran a survey among academics, to model their average response to time-allocation patterns among their colleagues, and based on this, they model pay-off functions for academics to devote certain percentage of their time in each of the above-mentioned activities. However, they do not derive equilibrium solutions which would be optimal for academics given the work allocating patterns of their colleagues; instead, they derive results about the level of integrity prevalent among the academics that they surveyed, based on their input in time management systems. Even though academics may at whiles work in particular projects, and the title of this paper explicitly mentions project management, the relevance of this work to the field of project management would have to be considered limited, since ultimately it models the working patterns of academics which are not necessarily time-bound.

Wei et al. (2018) [86] discuss a psychological contract that exists in people's minds, rather than a physical contract that exists on paper, in settings where collaboration occurs between individuals who have specialist knowledge (such as academic researchers). They use game theory to model such contracts. They use an extensive set of parameters which are attributes of the individuals concerned (such as their age, seniority, professional status etc.), as well as attributes of the collaboration itself (such as collaboration risk, length of collaboration etc.) to model pay-off functions for the individuals, and based on this, provide a game-theoretic solution which determines the 'terms' of the contract (such as how much time and effort each individual will commit into the collaboration etc.). The concept of "psychological contract" is novel in our context, and clearly of relevance to project management. However, the paper does not explicitly mention project management and neither does it highlight the relevance to project management.

There are several other papers which address ongoing contractual and/or managerial issues, and thus do not qualify to be considered papers that directly address project management problems and thus be included in our classification. For example, Barth et al. (2012) [87] discusses a (continuous) resource management problem, and its solution using game theory, in an interdomain routing network. Since the management seems to be an ongoing issue and not time bound, this is outside the ambit of project management. Mobarakeh et al. (2013) [88] presented a game-theoretic framework to determine the price of energy based on distributed generation. Again, this paper develops an activity which is ongoing, and cannot be defined as a project: as such, this paper is outside the scope of our review. Similarly, Pinto et al. (2015) [89] introduced a game-theoretic framework to model the decision-making behaviour of electricity market players in bilateral negotiations. Contracts made by such players among themselves have varying timespans, but do not reflect the time bound nature of projects, and may last for any length of time. Thus, this paper is not necessarily about project management and does not fall under the scope of this review. Elfakir and Tkiouat (2015) [90] discuss a profit sharing contract based on religious scriptures (called the Musharakah contract). They use game-theoretical modelling to compare the pay-offs for players under effort-based and output-based Musharakah contracts. The context explained by them makes clear that the Musharakah contract is intended as a model for long term profit sharing among business partners, and not intended to be applied in a 
project management context. Thus, this paper is outside the scope of our review. Kim and Kwak (2007) [91] deal with using game theory to model the bargaining process of long-term replenishment contracts between supplier and buyer; the contracts are explicitly stated to be negotiated on a long term basis and not for particular projects, and thus this paper is not within scope of the present review (We have reviewed other papers which deal with very similar problems specifically within a project management perspective, such as Lippman et al. [83] and Li et al. [64]). Li (2014) [92] offers a game-theoretic perspective on information technology outsourcing, by focusing on particular the information that must necessarily be shared as part of an outsourcing deal, and thus can be exploited by firms. They show that exploitation of sensitive information depends on the believe held by the firms about the future potential of the contracts, and service providers have higher incentive to exploit sensitive information about the client when they believe that future potential of the outsourcing contract is not great. Even though outsourcing can happen in the context of a project as well as in the business-as-usual (day to day operation) context of a firm, this paper does not specifically show any project management related examples, and thus is outside the scope of our review. Liu et al. (2017) [93] deals with contract negotiation within the context of electricity generation: therefore, game theory is used in an ongoing issue and not a project management issue here. Thus, this paper also is out of scope for our review.

There are also several papers which appear to have relevance to project management, but do not directly provide examples in the project management context (being under no constraint to do so), and thus could not be included in our classification process. For example, Watson (2013) [94] proposes a (rather general and abstract) modelling framework for contracts involving multi-period settings, with both self enforcement and external enforcement. A notion of contractual equilibrium, which combines a bargaining solution and individual incentive constraints, is proposed and analysed. The paper may have relevance to project management scenarios, but this is not very clear at the outset, and the paper does not delve into practical examples which are necessarily time bound, since the author is under no constraint to specify whether the scenarios are relevant to project management or not. Burato and Christani (2007) [95] present a zero-sum bargaining game to model the meaning negotiation problem in formal contract negotiation. Again, this could have applications to project management but a project management example per se is not presented, and the authors, under being no constraint to do so, do not clarify whether their modelling is relevant to project management scenarios.

Finally, Peldschus (2005) [96] also could be mentioned as an example here. This paper does not directly address game theory, but discusses decision-making in engineering, particularly civil engineering. Their method addresses multicriteria decision-making in construction projects using fuzzy sets and matrix game theory in the context of incomplete information. Therefore, strictly speaking, this study is outside the scope of our review.

\subsection{Gaps in Literature}

Our classifications illustrate potential areas of research where sufficient effort has not yet been extended. For example, considering Figure 1, it can be observed that game-theoretic concepts have not been applied sufficiently in ICT project management. This is somewhat surprising because game theory has been applied in wider ICT or computer scientific contexts quite often. For instance, several studies in the field of networked computing systems have modelled the dynamics of these systems as games between self-interested players. Examples include TCP congestion control, computer security level allocation, peer-to-peer routing, peer-to-peer overlay network formation and peer-to-peer file sharing patterns [97-101]. Nevertheless, there has not been sufficient research in using game theory for modelling ICT project management specifically. Similarly, considering Figure 3, note that certain types of games are not frequently used to model project management scenarios. These include extensive-form zero-sum non-cooperative games, as well as extensive-form cooperative games. Although a researcher typically chooses the problem they are interested in studying and then chooses a form of game appropriate to model that problem, and not vice versa, it is illuminating that project management 
scenarios do not seem to lend themselves often to be modelled as either extensive-form zero-sum non-cooperative games or extensive-form cooperative games. Nevertheless, it should be noted that the relative complexity of extensive-form games might be a reason why some types of extensive-form games are not often used. We have not found any paper in the niche that we reviewed that uses extensive-form zero-sum games. There was a single paper which used extensive-form cooperative games (Sacks and Harel, 2006 [84]), however even this paper was modelling a scenario where in an extended interaction, competition turns into cooperation through trust. Here lies an important hint: extensive-form cooperative games could be particularly useful in scenarios where players are initially competitive, but develop trust and are induced to cooperate after several rounds of interactions. Such scenarios are certainly not uncommon in project management, so researchers that model such scenarios could perhaps consider using extensive-form cooperative games more often.

\section{Citation Network of Reviewed Papers}

In this section, we present a "citation network" of the 32 papers which were described and classified in this review. The purpose of this exercise is two-fold: (a) Understanding the relative importance of each paper in the field, and how it has inspired or guided other studies in the field. (b) Understanding how papers are grouped together in terms of citation patterns, with the view of highlighting which classifications are the most significant in terms of authors being aware of other papers falling under the same classification. The citation network is presented in Figure 5. While Figure 5 shows the un-annotated network, Figure 6, Figure 7, and Figure 8 respectively show the network annotated according to the three classifications-domain-based, player-based and game-based classifications, respectively. These in turn correspond to Figure 1, Figure 2 and Figure 3, respectively.

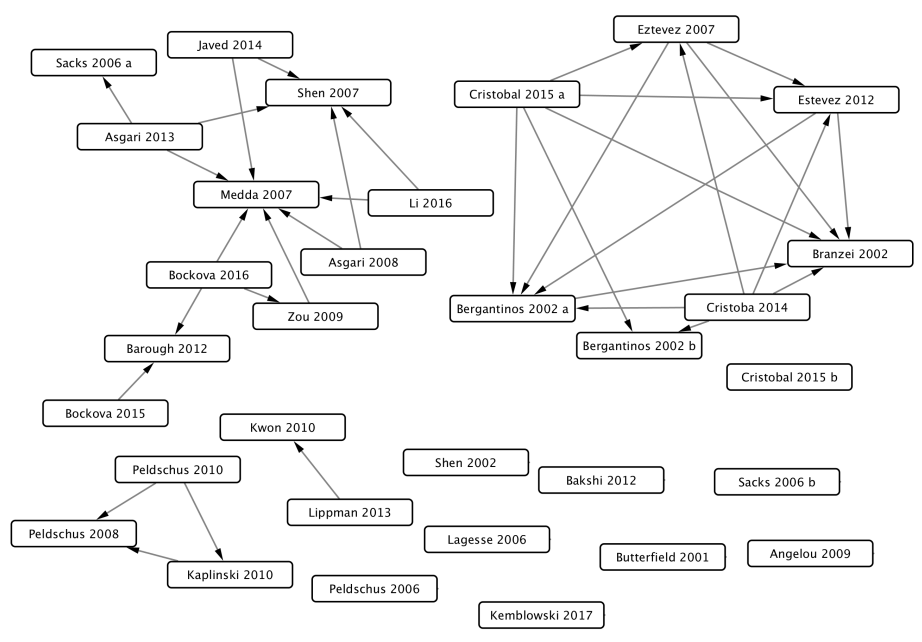

Figure 5. The citation network of papers reviewed—no classification shown.

In a citation network, the nodes are papers, and the links are citations from one paper to another, which are directed. We constructed the citation network of the 32 papers we have analysed, by manually checking which other papers within our review each of these papers have cited. This was possible, because the number of citations within the field was relatively sparse, there being only 34 instances where one paper from our review is cited by another. Therefore, the average out-degree of the citation network (the average number of times when a paper within the field, as we defined it, cited another within the field), was only 1.0625, indicating that, in general, studies about the use of game theory in project management were conducted without much awareness, or the explicit expression of such awareness, of other studies in the field. Quite often, we found that the authors cited only their own work in the field, or the work of close collaborators. Of course, each paper made a number of citations to papers outside the field, due to their relevance to project management or game theory but not both, 
which is justifiable. In fact, the average number of papers cited by papers we reviewed (the average length of the reference list of the papers we reviewed) is 35.0, which means that most of the citations were made to papers which were outside the niche that we review.

The citation network we constructed is shown in Figure 5. It could be immediately observed that there are two large clusters, two small clusters, and nine singleton papers. Medda (2007) is at the centre of one large cluster (henceforth called the "Medda cluster"), and the other large cluster seems to be composed of papers written by Cristobal each citing several others not written by Cristobal (henceforth called the "Cristobal cluster"). The smaller clusters consist of citations among papers of the same author or his collaborators (Peldschus in the first case, Lippman in the second, henceforth called "Peldschus cluster" and "Lippman cluster", respectively).

In order to understand how the large clusters were formed, we now proceed to highlight the "type" of papers, according to our classification scheme, in Figures 6-8 below. Accordingly, Figure 6 highlights the domain-based classification, Figure 7 highlights the classification based on the type of players, and Figure 8 highlights the classification based on the type of game used. Since the third classification is a complex matrix classification, we consider only the four basic types of games in this figure: normal-form non-cooperative games, normal-form cooperative games, extensive-form non-cooperative games and extensive-form cooperative games. The node colour indicates the class each node belongs to in each figure, as indicated in the caption of each figure.

From Figure 6, we can see that the large clusters are composed of construction industry papers or generic papers (many of which are nevertheless inspired by the construction industry). The Medda cluster and Peldschus cluster are predominantly composed of construction industry papers, while the Cristobal cluster is composed of author Cristobal, focusing on construction industry, citing a number of generic project management papers in each of their works. The few ICT domain papers present are singletons, apparently not being aware of each other. It should be noted particularly that the one Feldschus paper that we have classified as 'generic' lies outside of the Peldschus cluster, not citing or being cited by any of his other works.

However, the clustering patterns become clearer when we consider the player-based, and game-based classifications, as shown in Figures 7 and 8 . It could be observed that the "Cristobal cluster" is composed of papers employing normal-form cooperative games, and modelling subcontractor-subcontractor interactions. Hence they are tightly clustered in terms of citations. The Medda cluster is more diverse, though it seems to focus primarily on public-private partnerships (government-contractor games). The Peldschus cluster focuses on normal-form non-cooperative games. The Lippman cluster focuses on extensive-form non-cooperative games which are between a contractor and a subcontractor. Therefore, we may see that all three classifications we presented above influence the citation patterns in the field.

In terms of relative importance within the field (niche) that we considered, it is obvious from Figure 5 that Medda (2007), Branzei et al. (2002), Bergantinos and Sanchez (2002), Estevez-Fernandez (2012) and Shen et al. (2007), in that order, are cited the most times from within the field. Thus, these papers occupy the most prominent positions within the citation network of the field, and have presumably had the most influence on other papers within the field. For comparison, we present in Figure 9 the Google Scholar citation counts of each paper that we have reviewed and classified (as they stood on the 4 April 2019). Here, obviously the citations are from papers in any field, not just in the particular niche that we are reviewing. The number of references in the reference list of each paper is also presented for completeness. Comparing this with Figure 5, we may note unsurprisingly that the Medda, 2007 paper, which is at the centre of the Medda cluster, is also the most cited paper overall. The papers by Shen et al. are the next most cited, one of which is also in the Medda cluster, and cited by many other papers in the field. A paper by Peldschus which belongs to the Peldschus cluster is also among the most cited. Therefore, there is close correlation between the reception and impact of a paper within the niche, and its overall reception and impact in the wider scientific community. However, 
since the citation network within the niche is sparse, the number of times papers are cited within the niche is a lot smaller than the number of times they are cited overall.

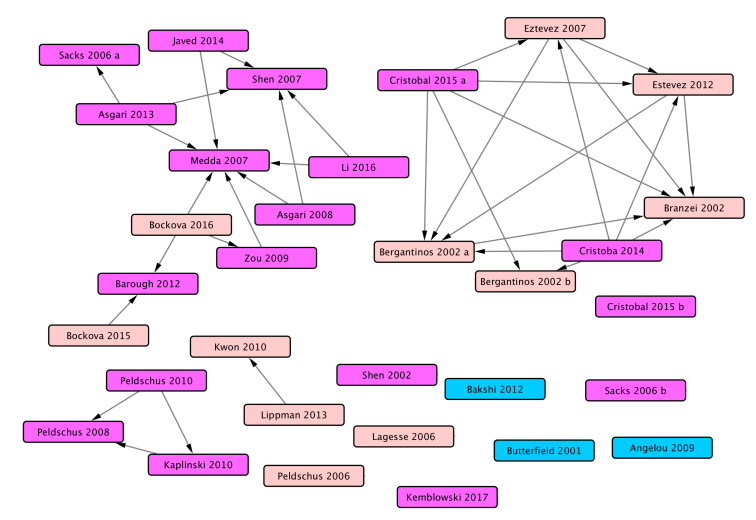

Figure 6. The citation network of papers reviewed-domain-based classification shown. Bright pink: construction domain; blue: ICT domain; brownish-pink: other domains or generic project management.

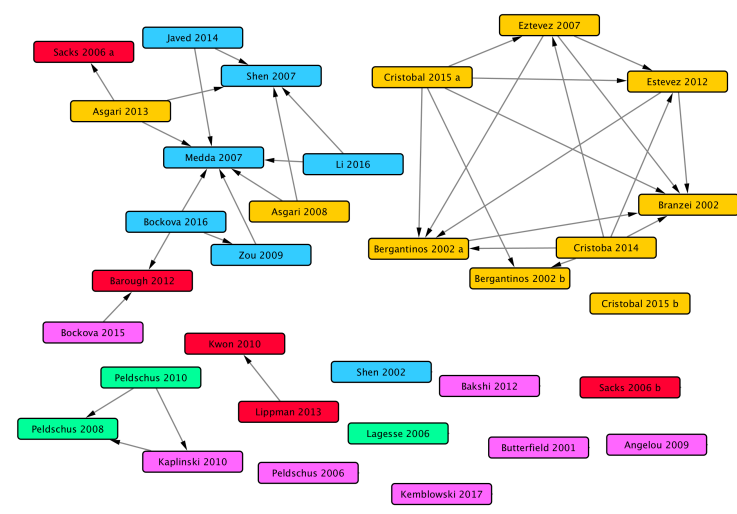

Figure 7. The citation network of papers reviewed-player-based classification shown. Blue: government sector-private sector game; pink: contractor-contractor game; red: contractorsubcontractor game; yellow: subcontractor-subcontractor game; green: other types of players.

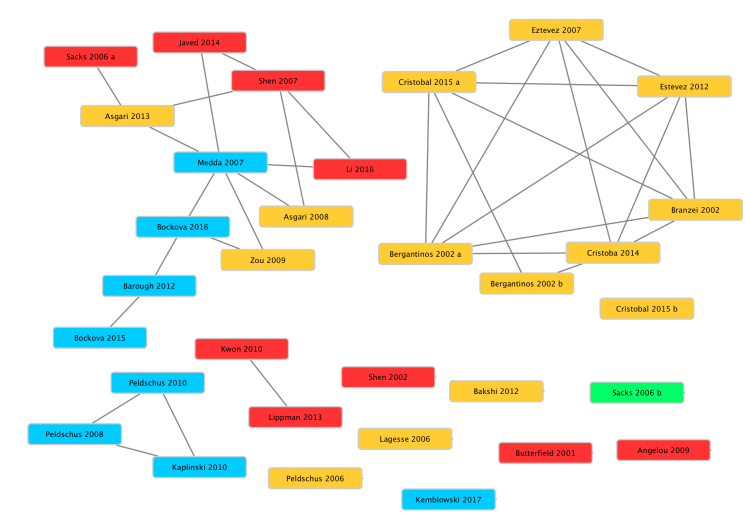

Figure 8. The citation network of papers reviewed-game-based classification shown. Blue: normal-form non-cooperative game; yellow: normal-form cooperative game; red: extensive-form non-cooperative game; green: extensive-form cooperative game. 


\begin{tabular}{|c|c|c|c|c|}
\hline Paper ID & $\begin{array}{l}\text { Paper name (First } \\
\text { author name + } \\
\text { publication year) }\end{array}$ & $\begin{array}{l}\text { Google scholar } \\
\text { citations } \\
\text { (incoming } \\
\text { citations) }\end{array}$ & $\begin{array}{l}\text { Number of } \\
\text { references } \\
\text { (outgoing } \\
\text { citations) }\end{array}$ & $\begin{array}{l}\text { Rank based on } \\
\text { incoming } \\
\text { citations }\end{array}$ \\
\hline 1 & Angelou 2009 & 46 & 48 & 10 \\
\hline 2 & Asgari 2013 & 33 & 60 & 13 \\
\hline 3 & Asgari 2008 & 14 & 12 & 22 \\
\hline 4 & Bakshi 2012 & 3 & 15 & 29 \\
\hline 5 & Barough 2012 & 43 & 32 & 11 \\
\hline 6 & Bergantinos 2002 a & 35 & 9 & 12 \\
\hline 7 & Bergantinos 2002 b & 18 & 10 & 20 \\
\hline 8 & Bockova 2015 & 14 & 22 & 22 \\
\hline 9 & Bockova 2016 & 1 & 30 & 30 \\
\hline 10 & Branzei 2002 & 51 & 19 & 6 \\
\hline 11 & Butterfield 2001 & 22 & 13 & 18 \\
\hline 12 & Cristoba 2014 & 9 & 57 & 26 \\
\hline 13 & Cristobal 2015 a & 12 & 80 & 25 \\
\hline 14 & Cristobal 2015 b & 1 & 18 & 30 \\
\hline 15 & Estevez 2012 & 49 & 24 & 9 \\
\hline 16 & Eztevez 2007 & 28 & 5 & 16 \\
\hline 17 & Javed 2014 & 30 & 127 & 15 \\
\hline 18 & Kaplinski 2010 & 51 & 131 & 6 \\
\hline 19 & Kemblowski 2017 & 1 & 8 & 30 \\
\hline 20 & Kwon 2010 & 33 & 26 & 13 \\
\hline 21 & Lagesse 2006 & 19 & 6 & 19 \\
\hline 22 & Li 2016 & 13 & 63 & 24 \\
\hline 23 & Lippman 2013 & 26 & 33 & 17 \\
\hline 24 & Medda 2007 & 308 & 24 & 1 \\
\hline 25 & Peldschus 2008 & 63 & 33 & 5 \\
\hline 26 & Peldschus 2006 & 4 & 0 & 28 \\
\hline 27 & Peldschus 2010 & 50 & 87 & 8 \\
\hline 28 & Sacks 2006 a & 78 & 44 & 4 \\
\hline 29 & Sacks 2006 b & 17 & 18 & 21 \\
\hline 30 & Shen 2002 & 194 & 9 & 2 \\
\hline 31 & Shen 2007 & 161 & 29 & 3 \\
\hline 32 & Zou 2009 & 7 & 28 & 27 \\
\hline
\end{tabular}

Figure 9. Citation counts of the papers classified according to Google scholar, as accessed on the 4 April 2019. The number of references in each paper is also shown; that is, the incoming citations and outgoing citations of each paper we reviewed are shown. The publication year of the paper is mentioned as part of the paper name. 


\section{Conclusions}

Several project management scenarios where decision-making takes place lend themselves to be modelled using game theory. A considerable number of studies have applied game-theoretic analysis in project management, however a concise review of such efforts was lacking. In this review paper, we undertook the exercise of systematically searching, selecting and reviewing papers which have used game-theoretic analysis in project management. We also proposed a set of classifications which structure and define this niche, and demonstrated the importance of such classifications. We analysed the relative importance and impact of the papers reviewed, and identified gaps in the literature which represent future research opportunities.

Our analysis showed that papers in this field can be classified based on the domain of application, the way the players are modelled, or the type of game utilised. In terms of the domain, papers focusing on construction domain are the most prominent, though there are also papers that focus on the ICT domain, as well as generic project management focused papers. In terms of modelling the players, we showed that five classes of papers exist: papers that model government-private sector games, papers that model contractor-contractor games, papers that model contractor-subcontractor games, papers that model subcontractor-subcontractor games and papers that model games involving other players. In terms of the type of games used, we showed that a complex matrix-based classification exists, though the four basic classes present are papers which use normal-form non-cooperative games, papers which use normal-form cooperative games, papers which use extensive-form non-cooperative games and papers which use extensive-form cooperative games. Based on these classifications, we showed that papers which focus on ICT domain, as well as papers which use extensive-form cooperative games, are relatively few in number, representing gaps in literature.

We also showed that within the niche, a paper is more likely to cite another paper if they are both focusing on the same application domain, or use the same types of games. In particular, we showed that two large "citation clusters" exist: papers which use non-cooperative games mainly in the construction domain, and papers that use normal-form cooperative games which are generic project management focused and not specific to any application domain. Overall, we made a very strong case for the widespread use of game theory to model and analyse project management-related scenarios, by highlighting a range of scenarios where it could be used, and the types of games which could be used in each such scenario.

Even though there have been some efforts in the past to summarise efforts made in applying game theory to project management, they have been focused on specific authors, countries or application domains. This review, on the other hand, employed a principled and methodical selection process which was not centred on any author, country or application domain. This review also put emphasis on structuring, classification and citation-analysis of the literature that it covered. It also focused explicitly and methodically on citation relationships between the papers that it reviewed, highlighting how the works are interrelated and which papers acted as catalysts for further research in the field.

This review highlighted that game theory is a very useful tool to analyse project management scenarios, and efforts to apply game-theoretic analysis in project management have great potential, but at present this is a nascent field. Studies in this niche are often not aware of each other and the citation density within the niche is relatively low. Therefore, it is important that more collaboration efforts take place among researchers which apply game theory in project management, spanning domains and choice of games. It is expected that this review will be a catalyst for increased interest in applying game theory in project management, and will encourage cross-domain collaboration and sharing of expertise to realise the full potential of game theory in analysing project management problems.

Funding: This research received no external funding. 
Acknowledgments: Students and tutors from the unit of study of "Data Analysis for Project Management" at the University of Sydney during years 2013-2018 are gratefully acknowledged for their many insightful questions and discussions.

Conflicts of Interest: The author declares no conflicts of interest.

\section{References}

1. A Guide to the Project Management Body of Knowledge (PMBoK Guide), 5th ed.; Project Management Institute: Pennsylvania, PA, USA, 2013.

2. Rose, K.H. A Guide to the Project Management Body of Knowledge (PMBOK® Guide) Fifth Edition. Proj. Manag. J. 2013, 44, e1. [CrossRef]

3. A Guide to the Project Management Body of Knowledge (PMBoK® Guide), 2000 ed.; Project Management Institute: Pennsylvania, PA, USA, 2001.

4. Williams, T.M. Managing and Modelling Complex Projects; Springer: Berlin/Heidelberg, Germany, 2013.

5. Williams, T. The contribution of mathematical modelling to the practice of project management. IMA J. Manag. Math. 2003, 14, 3-30. [CrossRef]

6. Osborne, M.J. An Introduction to Game Theory; Oxford University Press: New York, NY, USA, 2004.

7. Von Neumann, J.; Morgenstern, O. Game Theory and Economic Behavior; Joh Wiley and Sons: New York, NY, USA, 1944.

8. Kasthurirathna, D.; Piraveenan, M.; Harré, M. Influence of topology in the evolution of coordination in complex networks under information diffusion constraints. Eur. Phys. J. B 2014, 87, 3. [CrossRef]

9. Kasthurirathna, D.; Piraveenan, M. Topological stability of evolutionarily unstable strategies. In Proceedings of the 2014 IEEE Symposium on Evolving and Autonomous Learning Systems (EALS), Orlando, FL, USA, 9-12 December 2014; pp. 35-42.

10. Kasthurirathna, D.; Nguyen, H.; Piraveenan, M.; Uddin, S.; Senanayake, U. Optimisation of strategy placements for public good in complex networks. In Proceedings of the 2014 International Conference on Social Computing, Beijing, China, 4-7 August 2014; ACM: New York, NY, USA, 2014; p. 1.

11. Kasthurirathna, D.; Harre, M.; Piraveenan, M. Optimising influence in social networks using bounded rationality models. Soc. Netw. Anal. Min. 2016, 6, 54. [CrossRef]

12. Peldschus, F. Experience of the game theory application in construction management. Technol. Econ. Dev. Econ. 2008, 14, 531-545. [CrossRef]

13. San Cristóbal, J.R. Management Science methods and methodologies for Project Management: What they model, how they model and why they model. Pmworldlibrary Net Viewed 2015, 15, 2017.

14. Bilton, C.; Cummings, S. Handbook of Management and Creativity; Edward Elgar Publishing: Cheltenham, UK, 2014.

15. Bočková, K.H.; Sláviková, G.; Gabrhel, J. Game Theory as a Tool of Project Management. Procedia Soc. Behav. Sci. 2015, 213, 709-715. [CrossRef]

16. Kapliński, O.; Tamošaitiene, J. Game theory applications in construction engineering and management. Ukio Technol. Ekon. Vystym. 2010, 16, 348-363, doi:10.3846/tede.2010.22. [CrossRef]

17. Dvir, D.; Sadeh, A.; Malach-Pines, A. Projects and project managers: The relationship between project managers' personality, project types, and project success. Proj. Manag. J. 2006, 37, 36-48. [CrossRef]

18. Cleland, D.I. The evolution of project management. IEEE Trans. Eng. Manag. 2004, 51, 396-397. [CrossRef]

19. Seymour, T.; Hussein, S. The history of project management. Int. J. Manag. Inf. Syst. (Online) 2014, 18, 233. [CrossRef]

20. Barough, A.S.; Shoubi, M.V.; Skardi, M.J.E. Application of Game Theory Approach in Solving the Construction Project Conflicts. Proced. Soc. Behav. Sci. 2012, 58, 1586-1593. [CrossRef]

21. Rasmusen, E.; Blackwell, B. Games and Information: An Introduction to Game Theory; Blackwell Publishing: Cambridge , MA, USA, 1994; Volume 2.

22. Kasthurirathna, D.; Piraveenan, M. Emergence of scale-free characteristics in socio-ecological systems with bounded rationality. Sci. Rep. 2015, 5, 10448. [CrossRef] [PubMed] 
23. Kasthurirathna, D.; Piraveenan, M.; Harre, M. Evolution of coordination in scale-free and small world networks under information diffusion constraints. In Proceedings of the 2013 IEEE/ ACM International Conference on Advances in Social Networks Analysis and Mining (ASONAM 2013), Niagara Falls, ON, Canada, 25-28 August 2013; pp. 183-189.

24. Thedchanamoorthy, G.; Piraveenan, M.; Uddin, S.; Senanayake, U. Influence of vaccination strategies and topology on the herd immunity of complex networks. Soc. Netw. Anal. Min. 2014, 4, 213. [CrossRef]

25. Perc, M.; Jordan, J.J.; Rand, D.G.; Wang, Z.; Boccaletti, S.; Szolnoki, A. Statistical physics of human cooperation. Phys. Rep. 2017, 687, 1-51. [CrossRef]

26. Bendor, J.; Swistak, P. Types of evolutionary stability and the problem of cooperation. Proc. Natl. Acad. Sci. USA 1995, 92, 3596-3600. [CrossRef] [PubMed]

27. Perc, M. Phase transitions in models of human cooperation. Phys. Lett. A 2016, 380, 2803-2808. [CrossRef]

28. Chen, X.; Perc, M. Optimal distribution of incentives for public cooperation in heterogeneous interaction environments. Front. Behav. Neurosci. 2014, 8, 248. [CrossRef] [PubMed]

29. Capraro, V.; Perc, M.; Vilone, D. The evolution of lying in well-mixed populations. J. R. Soc. Interface 2019, 16, 20190211. [CrossRef] [PubMed]

30. Helbing, D.; Brockmann, D.; Chadefaux, T.; Donnay, K.; Blanke, U.; Woolley-Meza, O.; Moussaid, M.; Johansson, A.; Krause, J.; Schutte, S.; et al. Saving human lives: What complexity science and information systems can contribute. J. Stat. Phys. 2015, 158, 735-781. [CrossRef] [PubMed]

31. Wang, Z.; Bauch, C.T.; Bhattacharyya, S.; d'Onofrio, A.; Manfredi, P.; Perc, M.; Perra, N.; Salathe, M.; Zhao, D. Statistical physics of vaccination. Phys. Rep. 2016, 664, 1-113. [CrossRef]

32. Chang, S.L.; Piraveenan, M.; Pattison, P.; Prokopenko, M. Game theoretic modelling of infectious disease dynamics and intervention methods: a mini-review. arXiv 2019, arXiv:1901.04143.

33. Chang, S.L.; Piraveenan, M.; Prokopenko, M. The effects of imitation dynamics on vaccination behaviors in SIR-network model. arXiv 2019, arXiv:1905.00734

34. Branzei, R.; Dimitrov, D.; Tijs, S. Models in Cooperative Game Theory; Springer Science \& Business Media: Berlin, Germany, 2008; Volume 556.

35. Brandenburger, A. Cooperative Game Theory: Characteristic Functions, Allocations, Marginal Contribution; Stern School of Business, New York University: New York, NY, USA, 2007; Volume 1, pp. 1-6.

36. Bell, M.; Perera, S.; Piraveenan, M.; Bliemer, M.; Latty, T.; Reid, C. Network growth models: A behavioural basis for attachment proportional to fitness. Sci. Rep. 2017, 7, 42431. [CrossRef] [PubMed]

37. Nash, J.F. Equilibrium points in n-person games. Proc. Natl. Acad. Sci. USA 1950, 36, 48-49. [CrossRef] [PubMed]

38. Kasthurirathna, D.; Piraveenan, M.; Uddin, S. Evolutionary stable strategies in networked games: The influence of topology. J. Artif. Intell. Soft Comput. Res. 2015, 5, 83-95. [CrossRef]

39. Kuhn, H.; Arrow, K.; Tucker, A. Contributions to the Theory of Games; Number v. 2 in Annals of Mathematics Studies; Princeton University Press: Princeton, NJ, USA, 1953.

40. Calcagno, R.; Kamada, Y.; Lovo, S.; Sugaya, T. Asynchronicity and coordination in common and opposing interest games. Theor. Econ. 2014, 9, 409-434. [CrossRef]

41. Schelling, T.C. The strategy of conflict. Prospectus for a reorientation of game theory. J. Confl. Resolut. 1958, 2, 203-264. [CrossRef]

42. Schelling, T.C. The Strategy of Conflict; Harvard University Press: Cambridge, MA, USA, 1980.

43. Lewis, D. Convention: A Philosophical Study; John Wiley \& Sons: Hoboken, NJ, USA, 2008.

44. Binmore, K. Playing for Real: A Text on Game Theory; Oxford University Press: Oxford, UK, 2007.

45. Hart, S. Games in extensive and strategic forms. In Handbook of Game Theory with Economic Applications; North Holland Publishing Company: Amsterdam, The Netherlands, 1992; Volume 1, pp. 19-40.

46. Von Stackelberg, H. Market Structure and Equilibrium; Springer Science \& Business Media: Berlin, Germany, 2010.

47. Nash, J.F., Jr. The bargaining problem. Econom. J. Econom. Soc. 1950, 18, 155-162. [CrossRef]

48. Rubinstein, A. Perfect equilibrium in a bargaining model. Econom. J. Econom. Soc. 1982, 50, 97-109. [CrossRef]

49. Smith, J.M. Evolution and the Theory of Games; Springer: Berlin/Heidelberg, Germany, 1993.

50. Newton, J. Evolutionary game theory: A renaissance. Games 2018, 9, 31. [CrossRef] 
51. Le, S.; Boyd, R. Evolutionary dynamics of the continuous iterated Prisoner's dilemma. J. Theor. Biol. 2007, 245, 258-267. [CrossRef] [PubMed]

52. Elsivier Scopus Database. Available online: www.scopus.com (accessed on 4 April 2019).

53. Amaruchkul, K. Game-theoretic Analysis of Air-cargo Allotment Contract. In Proceedings of the ICORES, Funchal, Portugal, 24-26 January 2018; pp. 47-58.

54. Szolnoki, A.; Wang, Z.; Perc, M. Wisdom of groups promotes cooperation in evolutionary social dilemmas. Sci. Rep. 2012, 2, 576. [CrossRef] [PubMed]

55. Ladley, D.; Wilkinson, I.; Young, L. The impact of individual versus group rewards on work group performance and cooperation: A computational social science approach. J. Bus. Res. 2015, 68, 2412-2425. [CrossRef]

56. Eberl, P. The development of trust and implications for organizational design: A game- and attributiontheoretical framework. Schmalenbach Bus. Rev. 2004, 56, 258-273. [CrossRef]

57. Staatz, J.M. The cooperative as a coalition: a game-theoretic approach. Am. J. Agric. Econ. 1983, 65, 1084-1089. [CrossRef]

58. Sexton, R.J. The formation of cooperatives: A game-theoretic approach with implications for cooperative finance, decision-making, and stability. Am. J. Agric. Econ. 1986, 68, 214-225. [CrossRef]

59. Peldschus, F.; Zavadskas, E.K.; Turskis, Z.; Tamosaitiene, J. Sustainable assessment of construction site by applying game theory. Inz. Ekon.-Eng. Econ. 2010, 21, 223-237.

60. Medda, F. A game theory approach for the allocation of risks in transport public private partnerships. Int. J. Proj. Manag. 2007, 25, 213-218. [CrossRef]

61. Shen, L.; Bao, H.; Wu, Y.; Lu, W. Using bargaining-game theory for negotiating concession period for BOT-type contract. J. Constr. Eng. Manag. 2007, 133, 385-392. [CrossRef]

62. Shen, L.; Li, H.; Li, Q. Alternative concession model for build operate transfer contract projects. J. Constr. Eng. Manag. 2002, 128, 326-330. [CrossRef]

63. Javed, A.A.; Lam, P.T.; Chan, A.P. Change negotiation in public-private partnership projects through output specifications: an experimental approach based on game theory. Constr. Manag. Econ. 2014, 32, 323-348. [CrossRef]

64. Li, Y.; Wang, X.; Wang, Y. Using bargaining game theory for risk allocation of public-private partnership projects: Insights from different alternating offer sequences of participants. J. Constr. Eng. Manag. 2016, 143, 04016102. [CrossRef]

65. Kembłowski, M.W.; Grzyl, B.; Siemaszko, A. Game Theory Analysis of Bidding for A Construction Contract. In IOP Conference Series: Materials Science and Engineering; IOP Publishing: Bristol, UK, 2017; Volume 245, p. 062047.

66. Bockova, K.H.; Slavikova, G.; Porubcanova, D. Game theory as a tool of conflict and cooperation solution between intelligent rational decision-makers in project management. J. Econ. Manag. Perspect. 2016, 10, 147-156.

67. Asgari, M.S.; Afshar, A. Modeling subcontractors cooperation in time; cooperative game theory approach. In Proceedings of the First International Conference on Construction in Developing Countries (ICCIDC-I), Karachi, Pakistan, 4-5 August 2008; pp. 312-319.

68. Asgari, S.; Afshar, A.; Madani, K. Cooperative game-theoretic framework for joint resource management in construction. J. Constr. Eng. Manag. 2013, 140, 04013066. [CrossRef]

69. Lagesse, B. A Game-Theoretical model for task assignment in project management. In Proceedings of the 2006 IEEE International Conference on Management of Innovation and Technology, Singapore, China, 21-23 June 2006; Volume 2, pp. 678-680.

70. San Cristóba, J.R. Cost allocation between activities that have caused delays in a project using game theory. Proced. Technol. 2014, 16, 1017-1026. [CrossRef]

71. San Cristóbal, J.R. The use of Game Theory to solve conflicts in the project management and construction industry. Int. J. Inf. Syst. Proj. Manag. 2015, 3, 43-58.

72. Bergantiños, G.; Sánchez, E. How to distribute costs associated with a delayed project. Ann. Oper. Res. 2002, 109, 159-174. [CrossRef]

73. Estévez-Fernández, A.; Borm, P.; Hamers, H. Project games. Int. J. Game Theory 2007, 36, 149-176. [CrossRef]

74. Estévez-Fernández, A. A game-theoretical approach to sharing penalties and rewards in projects. Eur. J. Oper. Res. 2012, 216, 647-657. [CrossRef] 
75. Brânzei, R.; Ferrari, G.; Fragnelli, V.; Tijs, S. Two approaches to the problem of sharing delay costs in joint projects. Ann. Oper. Res. 2002, 109, 359-374. [CrossRef]

76. Bergantiños, G.; Sánchez, E. NTU pert games. Oper. Res. Lett. 2002, 30, 130-140. [CrossRef]

77. Zou, W.; Kumaraswamy, M. Game theory based understanding of dynamic relationships between public and private sectors in PPPs. In Proceedings of the 25th Annual ARCOM Conference, Nottingham, UK, 7-9 September 2010; Association of Researchers in Construction Management: Manchester, UK, 2010.

78. Bakshi, T.; Sarkar, B.; Sanyal, S.K. A new soft-computing based framework for project management using game theory. In Proceedings of the 2012 International Conference on Communications, Devices and Intelligent Systems (CODIS), Kolkata, India, 28-29 December 2012; pp. 282-285.

79. Peldschus, F. Economical analysis of project management under consideration of multi-criteria decisions. Technol. Econ. Dev. Econ. 2006, 12, 169-170. [CrossRef]

80. Sacks, R.; Harel, M. An economic game theory model of subcontractor resource allocation behaviour. Constr. Manag. Econ. 2006, 24, 869-881. [CrossRef]

81. Angelou, G.N.; Economides, A.A. A multi-criteria game theory and real-options model for irreversible ICT investment decisions. Telecommun. Policy 2009, 33, 686-705. [CrossRef]

82. Butterfield, J.; Pendegraft, N. Analyzing information system investments: a game-theoretic approach. Inf. Syst. Manag. 2001, 18, 73-82. [CrossRef]

83. Lippman, S.A.; McCardle, K.F.; Tang, C.S. Using Nash bargaining to design project management contracts under cost uncertainty. Int. J. Prod. Econ. 2013, 145, 199-207. [CrossRef]

84. Sacks, R.; Harel, M. How Last Planner motivates subcontractors to improve plan reliability-A game theory model. In Proceedings of the 14th Annual IGLC Conference, Santiago, Chile, 25-27 July 2006.

85. de Magalhães, S.T.; Magalhães, M.J.; Sá, V.J. Establishment ofAutomatization as a Requirement for Time Management Input Modules in Project Management Information Systems for Academic Activities-A Game Theory Approach. Procedia Comput. Sci. 2015, 64, 1157-1162. [CrossRef]

86. Wei, W.; Wang, J.; Chen, X.; Yang, J.; Min, X. Psychological contract model for knowledge collaboration in virtual community of practice: An analysis based on the game theory. Appl. Math. Comput. 2018, 329, 175-187. [CrossRef]

87. Barth, D.; Boudaoud, B.; Mautor, T. Game theory for contracts establishment with guaranteed QoS in the interdomain network. In Proceedings of the 2012 International Conference on Communications and Information Technology (ICCIT), Hammamet, Tunisia, 26-28 June 2012; pp. 276-280.

88. Mobarakeh, A.S.; Rajabi-Ghahnavieh, A.; Zahedian, A. A game-theoretic framework for DG optimal contract pricing. In Proceedings of the IEEE PES ISGT Europe 2013, Lyngby, Denmark, 6-9 October 2013; pp. 1-5.

89. Pinto, T.; Vale, Z.; Praça, I.; Pires, E.; Lopes, F. Decision support for energy contracts negotiation with game theory and adaptive learning. Energies 2015, 8, 9817-9842. [CrossRef]

90. Elfakir, A.; Tkiouat, M. New Projects Sharing Ratios under Musharakah Financing: A Repeated Game Theoretical Approach Using an Output versus a Proposed Effort Based Contract. Am. J. Appl. Sci. 2015, 12, 654. [CrossRef]

91. Kim, J.; Kwak, T. Game theoretic analysis of the bargaining process over a long-term replenishment contract. J. Oper. Res. Soc. 2007, 58, 769-778. [CrossRef]

92. Li, X. Relational contracts, growth options, and heterogeneous beliefs: A game-theoretic perspective on information technology outsourcing. J. Manag. Inf. Syst. 2014, 31, 319-350. [CrossRef]

93. Liu, X.; Wu, C.; Sun, Y.; Hu, Z.; Gaol, B.; Tang, Y. Bilateral Contract Transaction Model for Generation Companies and Large Consumers Based on Bayesian Game-Theoretic Approach. In Proceedings of the 2017 IEEE 7th Annual International Conference on CYBER Technology in Automation, Control, and Intelligent Systems (CYBER), Honolulu, HI, USA, 31 July-4 August 2017; pp. 306-310.

94. Watson, J. Contract and game theory: Basic concepts for settings with finite horizons. Games 2013, 4, 457-496. [CrossRef]

95. Burato, E.; Cristani, M. Contract clause negotiation by game theory. In Proceedings of the 11th International Conference on Artificial Intelligence and Law, Stanford, CA, USA, 4-8 June 2007; ACM: New York, NY, USA, 2007; pp. 71-80.

96. Peldschus, F.; Zavadskas, E.K. Fuzzy matrix games multi-criteria model for decision-making in engineering. Informatica 2005, 16, 107-120. 
97. Kasthurirathna, D.; Piraveenan, M.; Uddin, S. Modeling networked systems using the topologically distributed bounded rationality framework. Complexity 2016, 21, 123-137. [CrossRef]

98. Blanc, A.; Liu, Y.K.; Vahdat, A. Designing incentives for peer-to-peer routing. In Proceedings of the 24th Annual Joint Conference of the IEEE Computer and Communications Societies (NFOCOM 2005), Miami, FL, USA, 13-17 March 2005; Volume 1, pp. 374-385.

99. Christin, N.; Grossklags, J.; Chuang, J. Near rationality and competitive equilibria in networked systems. In Proceedings of the ACM SIGCOMM Workshop on Practice and Theory of Incentives in Networked Systems, Portland, OR, USA, 3 September 2014; ACM: New York, NY, USA, 2014; pp. 213-219.

100. Christin, N.; Chuang, J. On the cost of participating in a peer-to-peer network. In Peer-to-Peer Systems III; Springer: Berlin/Heidelberg, Germany, 2005; pp. 22-32.

101. Chun, B.G.; Fonseca, R.; Stoica, I.; Kubiatowicz, J. Characterizing selfishly constructed overlay routing networks. In Proceedings of the Twenty-third Annual Joint Conference of the IEEE Computer and Communications Societies (INFOCOM 2004), Hong Kong, China, 22 November 2004; Volume 2, pp. 1329-1339.

(C) 2019 by the author. Licensee MDPI, Basel, Switzerland. This article is an open access article distributed under the terms and conditions of the Creative Commons Attribution (CC BY) license (http:// creativecommons.org/licenses/by/4.0/). 